Cita bibliográfica: Ponce Herrero, G. (2018). El centro histórico de Orihuela (Alicante): de espacio patrimonial a espacio de rentas urbanas. Boletín de la Asociación de Geógrafos Españoles, 76, 183-217. doi: $10.21138 /$ bage. 2520

\title{
El centro histórico de Orihuela (Alicante): de espacio patrimonial a espacio de rentas urbanas
}

The historic quarter of Orihuela (Alicante): from heritage to urban revenue

\author{
Gabino Ponce Herrero \\ gabino.ponce@ua.es \\ Departamento de Geografía Humana \\ Universidad de Alicante (España)
}

\section{Resumen}

La ciudad de Orihuela reúne un rico patrimonio arquitectónico y urbanístico, heredado del Antiguo Régimen, muy afectado por la renovación impulsada por los primeros planes generales de ordenación urbana. Hasta 1994 no tuvo un plan especial que, no obstante, se vio alterado por la práctica del urbanismo de proyecto. Así, las estrategias desarrolladas sobre el centro histórico han podido orientarse hacia la producción de rentas urbanas. Son propuestas de rehabilitación selectiva junto a renovación masiva, apoyadas en las inversiones públicas en equipamientos para crear nuevas centralidades, que propician una recuperación aristocrática y tradicionalista, con una concepción muy sesgada de los paisajes históricos. Se mantiene la hipótesis de que la recuperación del centro histórico se orienta más hacia el negocio inmobiliario que hacia la rehabilitación de un espacio social.

Palabras clave: centro histórico; renovación; rentas urbanas.

\begin{abstract}
The town of Orihuela has a wealth of architectural and urban heritage, heir to the Ancien Régime, which has been strongly affected by the urban renewal promoted by the first general urban organisation plans. Prior to 1994 there was no special plan in place, but nonetheless it became
\end{abstract}


subject to the practice of project-based urban planning. Hence, the strategies developed with regard to the historic quarter have been geared towards the generation of urban revenues. The proposals are of selective rehabilitation together with massive renovation, supported by public investments in facilities to create new centralities. The latter favour aristocratic and traditionalist recovery, based on a highly biased conception of historical landscapes. The hypothesis that the recovery of the historical town centre is oriented more towards the real estate business than towards rehabilitating a social space is maintained.

Key words: historic quarter; renovation; urban revenues.

\section{Introducción}

El centro histórico de Orihuela (Alicante), como otros de alto nivel patrimonial, ha sido apropiado históricamente por la aristocracia y la Iglesia para el asiento de sus residencias y equipamientos. E espacio urbano genético, en la actualidad se muestra más como telón de fondo o escenario patrimonial, que acoge las grandes manifestaciones cívicas y religiosas, que como un barrio homogéneo. Inmerso en un proceso de abandono de las clases sociales que los construyeron, lo que ha favorecido la aparición de nuevos residentes, algunos de segmentos sociales muy desfavorecidos y de otras etnias y culturas, en proceso auspiciado por una larga estrategia de puesta en valor de la renta urbana de las grandes fincas de la Iglesia y la aristocracia local.

El negocio inmobiliario fue incorporando paulatinamente a los grandes propietarios locales de suelo -burguesía, nobleza y clero- conforme mermaban los ingresos de sus explotaciones agrarias. Si la afección general en el paisaje ha sido grave, más aún lo ha sido en el contexto urbano y, en especial, en el centro histórico de la ciudad. Ámbito en el que los propietarios han ido siempre por delante de las normas urbanísticas, o las han forzado con la aquiescencia general. ${ }^{1}$

\section{Marco teórico}

La pérdida de funcionalidad de los centros históricos es cuestión ya de largo recorrido, manifestada como problema generalizado desde los años 1970 (Terán, 1976), en que comienzan a aplicarse diferentes criterios de intervención, gracias a las nuevas exigencias del movimiento vecinal democrático y merced a la aparición de un nuevo marco legal, favorecedor de las intervenciones

1 Si se conseguía eludir las exigencias urbanísticas, se procedía a reemplazar la vieja casa por un nuevo edificio de viviendas. Si no, o bien se abandonaba o bien se negociaba con el Ayuntamiento y otras instituciones públicas para hacer entrega del inmueble al patrimonio público, a cambio de diversas prebendas, entre ellas, la de poder edificar en los huertos y patios anexos al caserón, o mejorar la edificabilidad en otros solares. 
en la ciudad consolidada, ${ }^{2}$ que superaban las limitaciones anteriores (Troitiño, 1992, p. 36) y abrían un nuevo abanico de posibilidades desde la rehabilitación hasta la renovación, tal como se ejecutaba en los años 1980 en la Reconstrucción de Barcelona (Bohigas, 1986, p. 141). Se defendía la intervención integral en beneficio de la vida y las funciones de los barrios antiguos, de la recuperación social y funcional de manera integrada (Campesino, 1989), en línea con las experiencias pioneras de Bolonia (Cervellati, Scannavini, 1976), frente a los postulados generalizados más conservacionistas -culturalistas, derivados de la pérdida constante del patrimonio arquitectónico y urbano debido al crecimiento industrial y al desarrollo de la ciudad moderna (González-Varas, 2008, p. 356) - , que han definido los criterios oficiales de intervención en los centros históricos valencianos, al menos hasta mediados los años 1990 (Gaja, 201, p. 283).

Cuando se aprueba el Plan Especial de Ordenación y Protección del Centro Histórico de Orihuela (PEOPCH) ya se ponían en cuestión los planes "de primera generación" centrados en la conservación de la arquitectura por encima de los aspectos sociales y funcionales (Boira, 1995: 245-249). El plan especial llegaba tarde en muchos sentidos, de forma que del análisis de la evolución de los criterios que se han seguido en la ciudad respecto de su núcleo genético -centro urbano a todos los efectos hasta los años 1970-, se observa la transición por los grandes debates urbanísticos, que son los que han marcado las normas de intervención genéricas en los centros históricos desde la segunda mitad del s. XX (Pol, 1998).

\subsection{Centro histórico o paisajes centrales históricos}

Si en el centro histórico el principal problema es el de la pérdida de funciones de centralidad, acompañado por el abandono residencial de las clases sociales propias del entorno, en los demás ámbitos históricos los problemas se centran en cuestiones sociales y de deterioro morfológico (Ponce, 2008). Temas que remiten a los problemas característicos de todos los centros históricos, o de sus áreas más humildes, pero también valiosas: "los paisajes residenciales sin cualidad son extremadamente útiles para el mantenimiento de la vida en la ciudad... y son patrimonio edificado" (Sargatal, 2003).

La conceptualización de las áreas centrales antiguas como paisaje ha sido estrategia propiciada por la UNESCO para la conservación y recuperación funcional de los conjuntos urbanos históricos, bien que con la ambigüedad que caracteriza tales declaraciones (Lalana, 2011). En la Conferencia celebrada en 2011, el punto 8 de las recomendaciones establecía la siguiente definición como nuevo enfoque para abordar los procesos de recuperación integral: "Se entiende por paisaje urbano histórico la zona urbana resultante de una estratificación histórica de valores y atributos

2 Reforma de Ley sobre Régimen de Suelo y Ordenación urbana y Texto Refundido, 1975/1976 que, entre otras disposiciones, se desarrolló mediante el Reglamento de Planeamiento (RD 2159/1978), el Reglamento de Gestión Urbanística (RD 3288/1978) y el Reglamento de disciplina urbanística (RD 2187/1978). 
culturales y naturales, lo que trasciende la noción de "conjunto" o "centro histórico" para abarcar el contexto urbano general y su entorno geográfico" (UNESCO, 2011).

En esencia se trata de abrir un nuevo abanico de posibilidades que, respetando el paisaje (insertándose armoniosamente en él o recomponiendo el hipotético paisaje mediante nuevos edificios tipológicos), permita a los habitantes de esos ámbitos históricos disponer de la calidad de vida y de las oportunidades que la ciudad contemporánea ofrece. En el caso de Orihuela, las principales carencias que merman la calidad de vida tienen que ver con la proximidad a servicios y equipamientos básicos, la movilidad y las deficiencias del parque de viviendas. Sin embargo, desde el primer plan general el foco de atención se ha centrado sobre el paisaje monumental y su conservación, desatendiendo otras cuestiones sustanciales relativas a la habitabilidad. Habría que esperar hasta el plan especial de 1994 para que tales aspectos se incluyeran en los programas de recuperación, bien que con escaso éxito, por marginales. Abordados ya directamente en 2009, con escasos recursos, mediante un programa específico de revitalización de los barrios del centro histórico.

\subsection{La recuperación ahistoricista o descontextualizada del centro histórico}

A mediados de los años 1990 se abre otro debate conceptual, después de una década de experiencias, al observarse la aplicación indistinta de estrategias de rehabilitación y renovación sobre los centros históricos. Es debate abierto que concita diversas opiniones después de varias décadas de experiencia en las intervenciones sobre tejidos urbanos antiguos (Lalana, 2011), al observarse casos en que la recuperación historicista enmascara estrategias de reconquista del espacio central para la Administración, los negocios y la elite, sustrayendo la cuestión social (García, 2005). En el caso de Orihuela, ceñida la observación al centro histórico, las operaciones efectuadas parecen incardinarse en esa dirección, a través de una recuperación "aristocráticotradicionalista", con una concepción muy parcial de los paisajes históricos, de hecho ahistórica, que se recrea en un momento concreto del pasado y rechaza otros.

Así, en el centro histórico de Orihuela se ha dado una primera etapa de rehabilitación sectorial, monumental o culturalista, que ha focalizado la atención en el edificio y su entorno más inmediato en la arquitectura-. Las disposiciones del primer y segundo PGOU de la ciudad identificaban tres zonas dentro del "Casco Antiguo", según su importancia "histórico-artística". Dentro de ellas, señalaban la prohibición de demoler total o parcialmente los edificios histórico-artísticos, pero permitían la sustitución de los edificios vecinos, favoreciendo la operación mediante el incremento de la edificabilidad de los nuevos.

Más tarde, se ha desarrollado otro enfoque conceptual, que tiene que ver con la idea de la especificidad del centro histórico, concebido como espacio cultural, icono de referencia y símbolo 
de pertenencia a una larga tradición señorial, aristocrática y eclesiástica, que lleva a considerarlo objeto de una planificación especial y al margen de las dinámicas propias del resto de la ciudad.

En los años 1980 ya se reivindicaba la conveniencia de la rehabilitación integrada de los centros históricos para evitar la desaparición de la simbología y las señas de identidad (Campesino, 1989, p. 15), al hacer balance de las actuaciones habidas en centros históricos, como el de Orihuela, afectados por una profunda renovación. Ahondando en esos criterios se ha llegado a lo que Álvarez considera "el mito del centro histórico" (Álvarez, 2006). Esto es, un espacio objeto de una ordenación específica - plan especial historicista, posibilista y rehabilitador- disociada de la del resto de la ciudad - plan general, positivista, expansivo y centrifugador de funciones-, al que se le asigna una función específica derivada de su monumentalidad -hito patrimonial-, que en opinión de Álvarez, cada vez se aleja más de la ciudad y de la ciudadanía con las que ha de convivir y lo convierte en un "mito", en un gran "proyecto arquitectónico especializado" que suplanta al planeamiento urbanístico integrado.

Se insertan en este debate dos nuevas derivadas. Una, resultante de la vieja dialéctica entablada entre recuperación icónica, cultural y simbólica para el aprovechamiento turístico, que propone varios productos turísticos asociados a su patrimonio urbano: Orihuela conjunto histórico-artístico, Orihuela paseo cultural, con diferentes rutas que ponen en valor los diferentes recursos que atesora el centro histórico. La otra, fruto del renovado interés por la recuperación de las rentas urbanas y realización de las plusvalías, por parte de las clases sociales casatenientes -nobleza, burguesía, iglesia- beneficiadas por las importantes inversiones públicas de las últimas dos décadas en ese escenario. Así, el suelo en el perímetro histórico se ha manifestado como un factor productivo de muy alto rendimiento, pese a la regulación que sobre el mercado establecen las normas urbanísticas recogidas en los planes generales. En Orihuela, como en los demás centros históricos, la escasez de suelo edificable ejerce un primer doble impacto: encarecimiento del existente y sustitución de edificios para ganar edificabilidad (Camagni, 2004, p. 168). Tales procesos son los que explicarían las propuestas de los dos primeros planes generales de Orihuela (1968 y 1973).

\subsection{La recuperación integrada y las cuestiones sociales}

Las propuestas de recuperación integral fueron calando, entre los gestores valencianos de centros históricos, desde las experiencias de Bolonia y Barcelona. Bajo esas nuevas directrices integradoras, en 1992 en Valencia arrancaba el Plan Rehabilitación Integral de Valencia (BOHIRA, 1995). Ese mismo año se aprobaba el Plan Rehabilitación y Arquitectura del Centro Histórico de Alacant, ampliado en 2003 con un nuevo Plan Integral de Recuperación del Centro Tradicional de Alicante, y en 2009 con un Plan Estratégico para la Revitalización Residencial y Económica del Casco Antiguo. Entre las grandes ciudades de la Provincia, también Alcoy aprobaba en 1992 el Plan 
Arquitectura y Rehabilitación de Alcoy, con visión integradora de las políticas sociales, funcionales y arquitectónicas, en sustitución del anterior PERI de 1986.

No obstante, en Orihuela, tanto por las carencias del PEOPCH, como por su incumplimiento, las áreas centrales históricas no se han beneficiado de una auténtica regeneración socioeconómica. De ese modo, el enfoque social de sus áreas centrales históricas ha tardado en incorporarse al debate ciudadano y, más aún, a las estrategias de gobierno local. Por ello, tardaría mucho en aprobarse el Plan Director de Revitalización de Barrios en el Casco Histórico 2009-2019, que ponía el acento en las cuestiones sociales, en la degradación morfológica de las áreas residenciales más modestas y en las carencias de servicios y equipamientos, bien que fiando la mayor parte de sus presupuestos a las ayudas estatales y europeas.

\subsection{Las nuevas relaciones entre el centro histórico y el resto del territorio}

El debate de la integración de las estrategias entre centro histórico y resto del territorio ha dado un salto cualitativo, al considerarse que la planificación de los centros históricos debe integrarse, en estos momentos de gran dispersión suburbana, no sólo con las dinámicas del resto de la ciudad, sino con las propias del sistema urbano territorial, articulado por grandes vías rápidas que favorecen la urbanización periférica, la configuración de entornos urbanos más o menos jerarquizados, o en forma de red -ciudad difusa-. En el caso del municipio de Orihuela, extensible a la comarca histórica y funcional del Bajo Segura, esa ciudad en red se va plasmando con una pérdida paulatina de capitalidad funcional, en favor de un policentrismo especializado, en el que destacan las muy dinámicas ciudades del litoral, como Torrevieja, y el propio ámbito litoral del municipio de Orihuela (denominado Orihuela-Costa que, en 2015 sumaba 25554 habitantes, o el $31 \%$ del total del municipio, frente a la ciudad compacta que, con 33000 habitantes suponía el $40 \%$ del total, cuando en el años 2000, Orihuela-Costa tan sólo alcanzaba el 10 \% y la ciudad el $50 \%)$.

Varias líneas de investigación contemporáneas (Troitiño y Gonzáles-Varas, 2015), centradas en la función de los centros históricos en las áreas metropolitanas o sistemas territoriales, proponen un nuevo enfoque en ese debate, al considerar que el patrimonio ha ampliado su escala de contenidos y funciones: primero del monumento a la calle, luego al barrio, más tarde a la ciudad y, en el presente a todo el sistema territorial del contexto. Sobre todo - pero no exclusivamente- desde una perspectiva paisajística, en la que el "paisaje histórico o monumental" sería una más de las unidades paisajísticas que configuran el territorio y, por ello, parte indisociable del mismo. En ese sentido, el Memorandum de Viena sobre Patrimonio Mundial y Arquitectura Contemporánea insistía en que la gestión del patrimonio se ha de integrar en los procesos de desarrollo local, de planificación urbana y de infraestructuras generales para, por un lado, no quedar al margen de 
esos potentes procesos y, por otra parte, influir con su presencia en el tratamiento paisajístico de esos desarrollos (UNESCO, 2011).

Ese novedoso enfoque considera que, pese a la mejora de la financiación, de los instrumentos y de los criterios de intervención, los centros históricos españoles han evolucionado "en paralelo" a los fenómenos expansivos de las periferias urbanas, muy afectados en sus objetivos por la enorme y creciente oferta de todo tipo que se asienta en esos espacios suburbanos y periurbanos, metropolitanos o en red.

Interesa esta perspectiva para el análisis del caso de Orihuela por cuanto se propone la reflexión sobre el papel del centro histórico en la configuración de nuevas centralidades, urbanas, morfológicas y simbólicas en el sistema territorial de referencia (González-Varas, 2015, p. 210), lo que constituye una oportunidad a medias explorada en el centro histórico de Orihuela, con dos tácticas muy precisas como han sido la apertura, en el año 2000, de un campus universitario dependiente de la Universidad Miguel Hernández, en un espacio de nueva gran accesibilidad, y la inauguración en 2006 de una nueva pseudo centralidad alrededor de un centro comercial de nueva generación (Ociopía), como todos junto a las grandes vías de comunicación, pero extraordinariamente pegado al centro histórico, al que parasita -vampiriza- más que complementa.

\section{Hipótesis, objetivos y fuentes}

A partir de ese marco teórico, se procede a analizar las figuras de planeamiento urbanístico que han regulado el centro histórico de la ciudad, para intentar valorar la influencia de cada uno de los enfoques apuntados en la actual configuración del centro histórico de Orihuela. Se sustenta la hipótesis de que el patrimonio arquitectónico y urbanístico generado por una aristocracia de base rural, que pudo haber sido importante patrimonio social, se ha visto profundamente afectado por el tránsito desde una economía de base agrícola hacia una economía basada en el negocio inmobiliario. Así, el trabajo se centra en los análisis de la edificabilidad permitida, como indicador de las transformaciones. En un contexto en el que sólo las últimas estrategias proponen recuperar de manera integral paisaje y funciones, ahora con marcada tendencia hacia el aprovechamiento turístico, recuperando el mito del centro histórico como espacio de valor cultural. El trabajo se apoya en el análisis de los planes generales, las modificaciones puntuales, los planes especiales, los catálogos de carácter municipal, del Catálogo de la Consellería de Cultura, de los valores catastrales, de las nuevas estratégicas de rehabilitación (planes y proyectos) para el turismo, del mercado de las viviendas, de los planes de rehabilitación de viviendas del Gobierno valenciano y en entrevistas a diferentes agentes socioeconómicos. 


\section{Origen y decadencia del patrimonio arquitectónico}

El rico patrimonio inmobiliario de la ciudad se halla directamente vinculado con la gran extensión y riqueza agrícola del término municipal que, con $384 \mathrm{~km}^{2}$, es el segundo más extenso de la Comunidad Valenciana. Cuenta con un importante terrazgo agrícola: 6988 Ha de secano y $12865 \mathrm{Ha}$ de regadío (Censo 2009). La prosperidad económica ha potenciado el papel de capitalidad de la ciudad a lo largo de la Historia, bajo las diversas adscripciones administrativas de Procuración General de Orihuela, Gobernación de Orihuela y, desde 1564 sede de una diócesis propia. La crisis de la ciudad desde finales del s. XVIII y el peso creciente del puerto de Alicante desencadenaron la elección de esta ciudad como capital de la provincia, demarcación a la que se adscribiría definitivamente Orihuela en 1833. El anquilosamiento de las estructuras sociales, junto al languidecimiento de las fortunas de base agrícola, condicionaron la creación de nuevos elementos patrimoniales en las centurias siguientes, y aún su mantenimiento. Desde mediados del s. XX, el negocio inmobiliario y las prácticas de renovación, amparadas en herramientas legales de ordenación urbana, marcaron la última impronta en el patrimonio urbanístico, que sólo fue catalogado oficialmente en 1990. 
Figura 1. Orihuela en 1848. Propiedades urbanas de la Iglesia

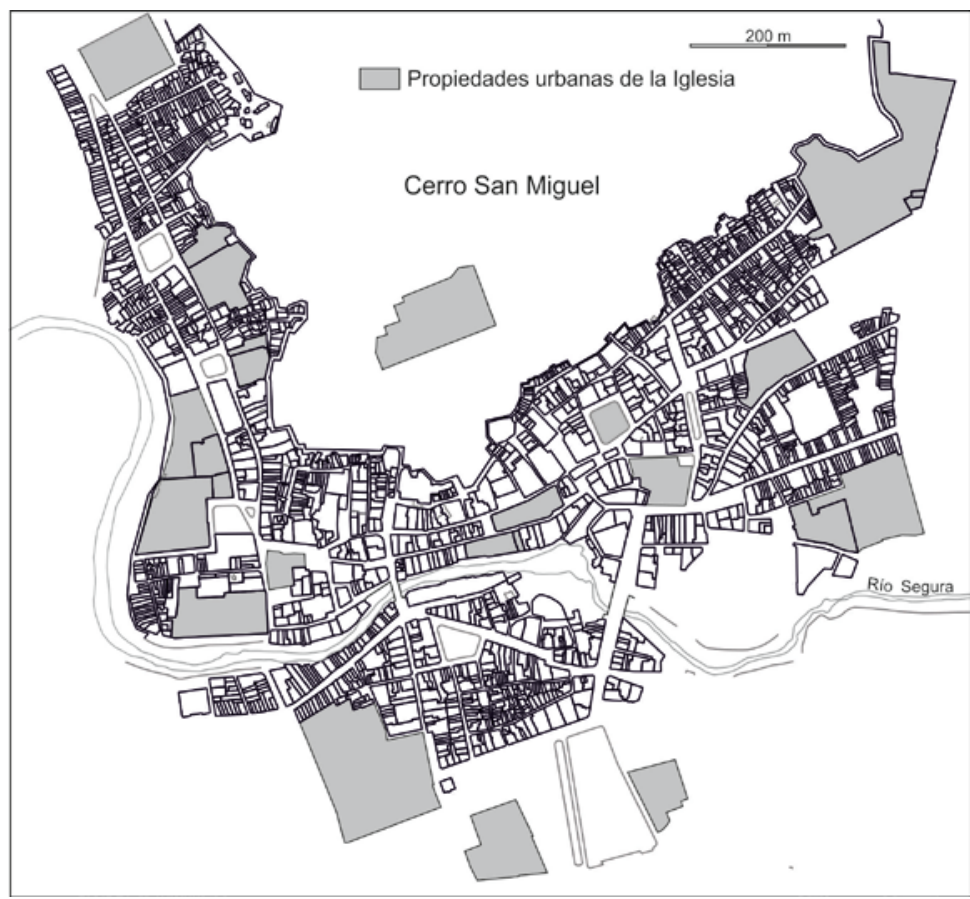

Fuente: elaboración propia a partir de Coello (1856)

\subsection{La gran propiedad agrícola como fundamento de la riqueza arquitectónica}

En el s. XVIII, el sistema enfitéutico medieval suponía un anacronismo, pero era bien recibo en Orihuela por cuanto además de los beneficios económicos para los propietarios, conllevaba también reconocimientos jurídicos y hasta prestigio social, al ser reconocidos los grandes propietarios (clero, nobleza y burguesía) como "señores de vasallos" (Gil y Canales, 1988). Es en el contexto de bonanza económica del s. XVIII cuando se genera la mayor riqueza arquitectónica de la ciudad. La nobleza y la burguesía local o modernizaron al gusto barroco sus palacios, o los construyeron ex novo. Por su parte, el clero enriquecido ampliaba las parroquias, levantaba nuevas fachadas barrocas y se afanaba en una potente misión constructora, levantando otras muchas instituciones para acoger al clero regular y secular, conventos diferenciados para hombres y mujeres, como los de los Mercedarios, los Dominicos (Colegio del Patriarca y universidad entre 1552 y 1835), los Agustinos, los Franciscanos, los Capuchinos, los Trinitarios, de San Sebastián, de las Agustinas, de las Dominicas, de las Clarisas y de las Capuchinas. Esas instituciones, sumadas a la Catedral y a las iglesias, ermitas, casas de misericordias y otras obras de carácter religioso erigidas en los diferentes barrios y pedanías de la ciudad, hicieron de Orihuela un verdadero crisol de estilos arquitectónicos, si bien, todos quedarían tamizados por la impronta del barroco, estilo adoptado como propio por la ciudad estamental del Antiguo Régimen. Pórticos góticos y patios renacentistas fueron modernizados por la máquina barroca de nuevas escenografías mucho más exuberantes, conforme con el espíritu de la Contrarreforma (Figura 1). 


\subsection{La decadencia económica y las primeras afecciones al patrimonio}

A principios del s. XIX la ciudad se vio afectada por varias circunstancias adversas concatenadas, que afectaron tanto a la construcción de nuevo patrimonio, como al mantenimiento del existente. Entre ellos, los efectos de la guerra de independencia, las afecciones de fiebre y cólera, las graves inundaciones de 1821 y 1834 y el terremoto de 1829 (con una modesta incidencia en el patrimonio edificado: derrumbes parciales en algunos edificios notables). Mas importante sería la prolongada etapa de decadencia vinculada con una crisis agrícola que, en opinión de varios autores (Aledo, 1990; Canales, Salazar, Crespo, 1992) se debió a la voluntad expresa de la oligarquía terrateniente de mantener a toda costa las estructuras sociales y económicas del Antiguo Régimen, poniendo freno al desarrollo económico y social del municipio.

Notable fue también la influencia de las reformas liberales de la centuria, que comenzaban con la paulatina supresión de los mayorazgos entre 1808 y 1836. Circunstancia que acabaría por debilitar a las grandes familias de la nobleza, limitando su capacidad de mantener o generar grandes edificios. Destacada fue, en ese sentido, la influencia de la abolición de los señoríos jurisdiccionales entre 1811 y 1837 (Gil, 1983). También afectó el proceso desamortizador, sobre las propiedades rústicas y urbanas del clero regular, a partir de 1836, y del secular desde 1841. En ese proceso, la aristocracia local (nobleza e Iglesia) perdía buena parte de los mismos recursos económicos que habían hecho posible la construcción de la ciudad monumental en la centuria anterior. Las rentas se aminoraban y dilapidaban, como indicaba el Cabildo catedralicio de la ciudad en 1851: "circunstancias adversas han influido en que le hayan abandonado multitud de ricos propietarios (consumiendo las rentas de su tierra en la Corte y otras capitales donde han fijado su domicilio)" (Canales, Salazar, Crespo, 1992).

\subsection{Las primeras medidas para la protección del patrimonio local}

La ciudad, estancada en su crecimiento (23 276 habitantes en 1787, 24300 hab. en 1877 y 28530 hab. en 1900), recibía a principios del s. XX los primeros reconocimientos oficiales a su patrimonio. La Gaceta de Madrid (núm. 155, de 4 de junio de 1931), recogía el Decreto del Ministerio de Instrucción Pública y Bellas Artes, de conformidad con la Ley de 1926 y a petición de la Junta Provincial para la protección, conservación y acrecentamiento del Tesoro Artístico Nacional, según el cual se declaraban "monumentos histórico-artísticos" la catedral de Orihuela, el convento de Santo Domingo y el castillo de la ciudad. La misma Gaceta (núm. 335, de 1 de diciembre de 1933), recogía la declaración como Monumento Nacional de la iglesia de Santiago Apóstol, en resolución de una instancia elevada al Ministerio por el propio párroco de la iglesia en el año 1925, con el informe favorable de la comisión provincial en 1932.

La Gaceta de la República (núm. 237, de 30 de septiembre de 1937) recogía la necesidad de crear en Orihuela una Subjunta delegada de incautación y protección del tesoro artístico, a 
instancias de la Junta Central del Tesoro Artístico, para paliar en lo posible la destrucción y desaparición del patrimonio artístico de Orihuela, muy afectado por su significado religioso y aristocrático, y por la clara oposición de la Iglesia a la II República, a través de sus centros de acción católica. No obstante, salvo el incendio del convento de Santa Lucía, los daños en el patrimonio inmueble fueron mínimos durante la guerra (menores que los ocasionados en el patrimonio mueble). De hecho, la principal afección, como con la desamortización, fue la privación de las rentas y del personal que mantenían los grandes inmuebles eclesiásticos.

Tras la guerra civil, la Diócesis de Orihuela desarrolló una intensa tarea para restaurar todo su poder en la ciudad, aupada en el apoyo absoluto del régimen triunfante. La tarea tuvo dos frentes: recuperar los privilegios seculares jurídicos y económicos y, al tiempo, recuperar el ejército humano de eclesiásticos (seculares y regulares) para mantener el patrimonio. A cambio, la lglesia mantenía la también secular tarea de legitimación de un régimen político autoritario. Los trabajos se inician ya en 1939, aprovechando la Ley de 2 de marzo de 1939 y Orden de 11 de marzo de 1939 por la que se declaraba la exención tributaria de los bienes de la Iglesia. En 1941 se creaba la Junta Nacional para la Reconstrucción de Templos Parroquiales, que gestionaba las ayudas del Estado, del propio Gobierno Civil de Alicante y los cuantiosos donativos voluntarios de la antigua aristocracia local, junto con otros donativos más o menos voluntarios (y aún forzados, como las subscripciones públicas en las parroquias o el trabajo físico de obreros en tareas de reconstrucción) de las nuevas asociaciones políticas y laborales: sindicatos católico-agrarios, colegio de abogados y comerciantes (Moreno, 1999, p. 39).

Los reconocimientos al patrimonio de la ciudad seguirían en pleno desarrollismo, bien que con un nuevo enfoque más aliado con el incipiente turismo de sol y playa y las primeras urbanizaciones que comenzaban a colonizar el litoral del municipio. De hecho desarrolladas sobre propiedades rústicas de la aristocracia oriolana (Vera, 1987, p. 192). En ese nuevo contexto socioeconómico, en 1951 se creaba el Ministerio de Información y Turismo, en 1962 la Dirección General de Promoción del Turismo, en 1960 se desarrollaba el Primer concurso de embellecimiento de pueblos en la provincia de Alicante. En Orihuela, por Decreto 2262 de 24 de julio de 1963 (BOE, n. 215) el Palmeral que flanquea el centro histórico de la ciudad (Palmeral de San Antón) se declaraba "paraje pintoresco" (hoy es "sitio histórico"), y en 1969 (BOE, n. 108 de 6 de mayo) se declaraba "conjunto histórico-artístico el sector antiguo de la ciudad de Orihuela" (Figura 2). Comenzaba a dársele un valor social al rico patrimonio privado de la ciudad, pero éste seguía desregulado, carente de una normativa eficaz que velase por su conservación. 
Figura 2. Orihuela. La evolución urbana hasta 1859 define el perímetro del centro histórico

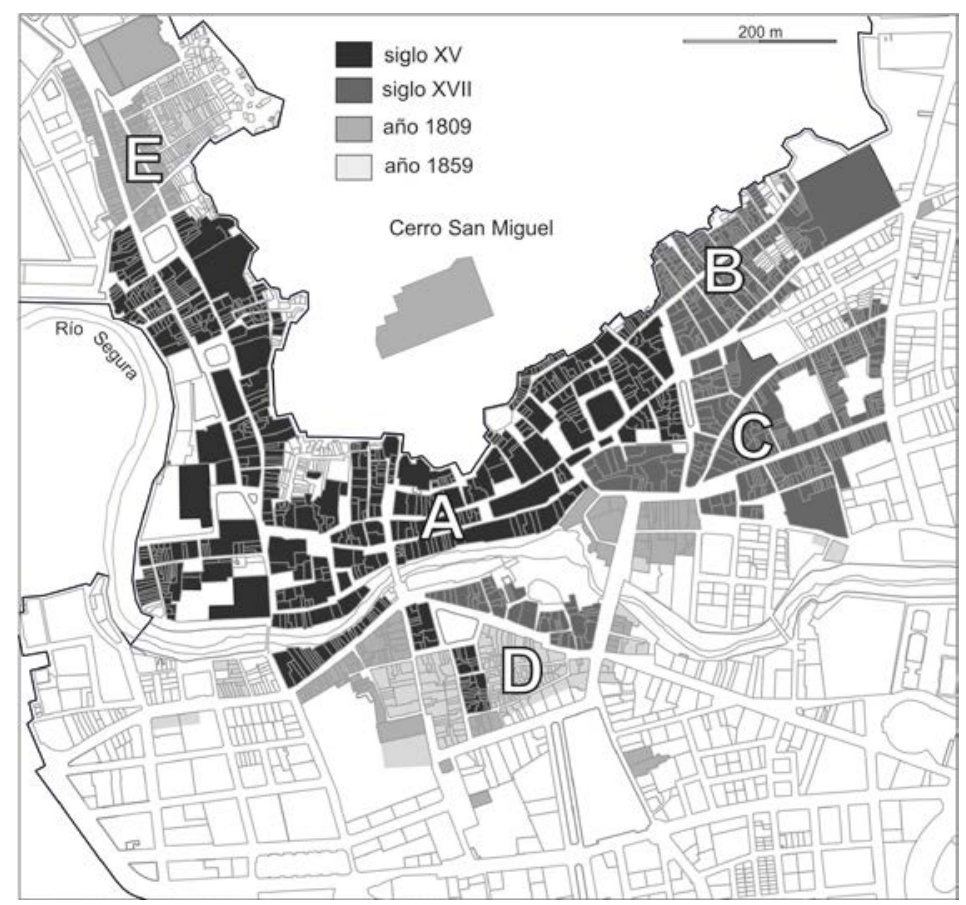

Leyenda: (A) Centro histórico; (B) Raval de la Porta Nova (hoy de Miguel Hernández o Calle de Arriba); (C) Raval de Sant Joan; (D) Raval Major (o de San Agustín) y Raval del Pont (o de la Mancebía); (E) Raval Roig (o Rabaloche).

Fuente: elaboración propia a partir de Aledo (1990) y Coello (1856)

\section{Los primeros planes de urbanismo y las transformaciones en el centro histórico}

La ciudad mantuvo un lento crecimiento hasta 1950 fundamentado en la intensificación de los cultivos y en la ampliación de los regadíos (en particular con la inauguración en 1926 de las infraestructuras de Riegos de Levante). No obstante, desde 1940 los crecimientos fueron inferiores a la media provincial y muy por debajo de los valores alcanzados por las ciudades industriales vecinas. Así, entre 1950 y 1970 el municipio permaneció estancado en parecido número de habitantes (44 979 en 1940 y 44938 en 1970). Más aún, la población de la cabecera municipal en 1950 era de sólo 14.198 habitantes. Esa es circunstancia que conviene retener para entender mejor los procesos urbanos experimentados por la ciudad en la segunda mitad del s. XX, con alta afección en el centro histórico. Orihuela es una ciudad estancada o de lento crecimiento dentro de en un municipio expansivo. Sobre ese reducto histórico se ha dejado sentir la influencia decisiva en las transformaciones formales del espacio urbano, de las medidas modernizadoras del urbanismo, desde el Reglamento de obras, servicios y bienes municipales de 1924, y, en especial, desde la Ley sobre Régimen del Suelo de 1956 y del Texto Refundido de 1976, que ampararon las primeras grandes transformaciones. 


\subsection{El primer documento de ordenación urbana y la dejación del ámbito patrimonial}

El primer Plan General de Ordenación urbana, tramitado entre 1957 y 1968, era documento obligado por la Ley del Suelo para los municipios con más de 50.000 habitantes, o para aquellos que quisiesen desarrollarlo de manera voluntaria. El municipio contaba con 44979 habitantes en 1950, pero la ciudad compacta tan sólo con 14198 habitantes. Podría haberse elegido la figura de un plan general, ante el despertar de la urbanización turística de su litoral, pero el lento crecimiento del número de habitantes del municipio, y el hecho de que la cabecera municipal contase con tan pocos habitantes, llevaron a la elección de "delimitar el perímetro del casco urbano y la zona de extensión" (BOE n. ${ }^{\circ}$ 135, 14 de mayo de 1956) para ordenar los crecimientos más urgentes.

De ese modo, el PGOU aprobado en 1968 sólo ordenaba el casco urbano de la ciudad, alegando que el municipio "carecía de unidad geográfica" (PGOU, 1990, Memoria 8) proponiendo que el resto del municipio fuese ordenándose de forma paulatina conforme con sus crecimientos. Circunstancia mantenida en revisiones posteriores, hasta que el plan general de 1990 abordara de manera integral todo el municipio. Paradójica por cuanto no se ordenaba en un plan general común todo el ámbito litoral, que era el que efectivamente experimentaba acelerados crecimientos.

Más aún, el PGOU de 1968 dejaba fuera de ordenación el Palmeral y el espacio afectado por la calificación de Conjunto Histórico-Artístico. En lo que respecta al Palmeral colindante con la ciudad, como paraje pintoresco quedaba bajo la protección del Estado, mediante tutela del Ministerio de Educación Nacional, que debía exigir "la más estricta observancia de las leyes del Tesoro Artístico, Municipal y Ensanche de Poblaciones" (BOE n. ${ }^{\circ} 215,07$ de septiembre de 1963). Sin embargo, pocas fueron las exigencias y, de hecho, de las "más de 60 Ha protegidas" que recoge el Decreto de 1963, en la actualidad quedan $40 \mathrm{Ha}$, habiendo sido ocupadas las restantes por diversos equipamientos públicos y edificaciones privadas, conforme con las posibilidades abiertas para tal fin por la revisión del PGOU en 1973.

Tras la declaración de "conjunto histórico-artístico del sector antiguo de la ciudad de Orihuela", era el Estado, a través del Ministerio de Educación y Ciencia, quién debía asumir la responsabilidad de su custodia (BOE n. ${ }^{\circ}$ 168, 6 de mayo de 1969). Quedaba pues el centro histórico adscrito a lo dispuesto en el Reglamento para la aplicación de la Ley del Tesoro Artístico Nacional (Decreto de 16 de abril de 1936; G. M. n. ${ }^{0}$ 108, 17 de abril de 1936) que explicitaba que "los planes de reforma interior y ensanche" de las poblaciones con conjuntos histórico-artísticos debían hacerse respetando los monumentos históricos, y para ello facultaba a la Junta Superior del Tesoro Artístico, a través de sus delegaciones, la misión de velar por la integridad de los mismos. Los redactores del PGOU aprovechaban para identificar los pocos edificios declarados de carácter monumental (Figura 3), definir la salvaguarda de esas piezas y establecer una ambigua "zona de influencia" de 
los mismos y dejar que fuese la Comisión Provincial del Tesoro Artísticos (creada en 1843 y renovada en 1939) quien velase por su conservación.

Figura 3. PGOU (1957-1968): perímetro del centro histórico y zonas de protección e influencia de monumentos

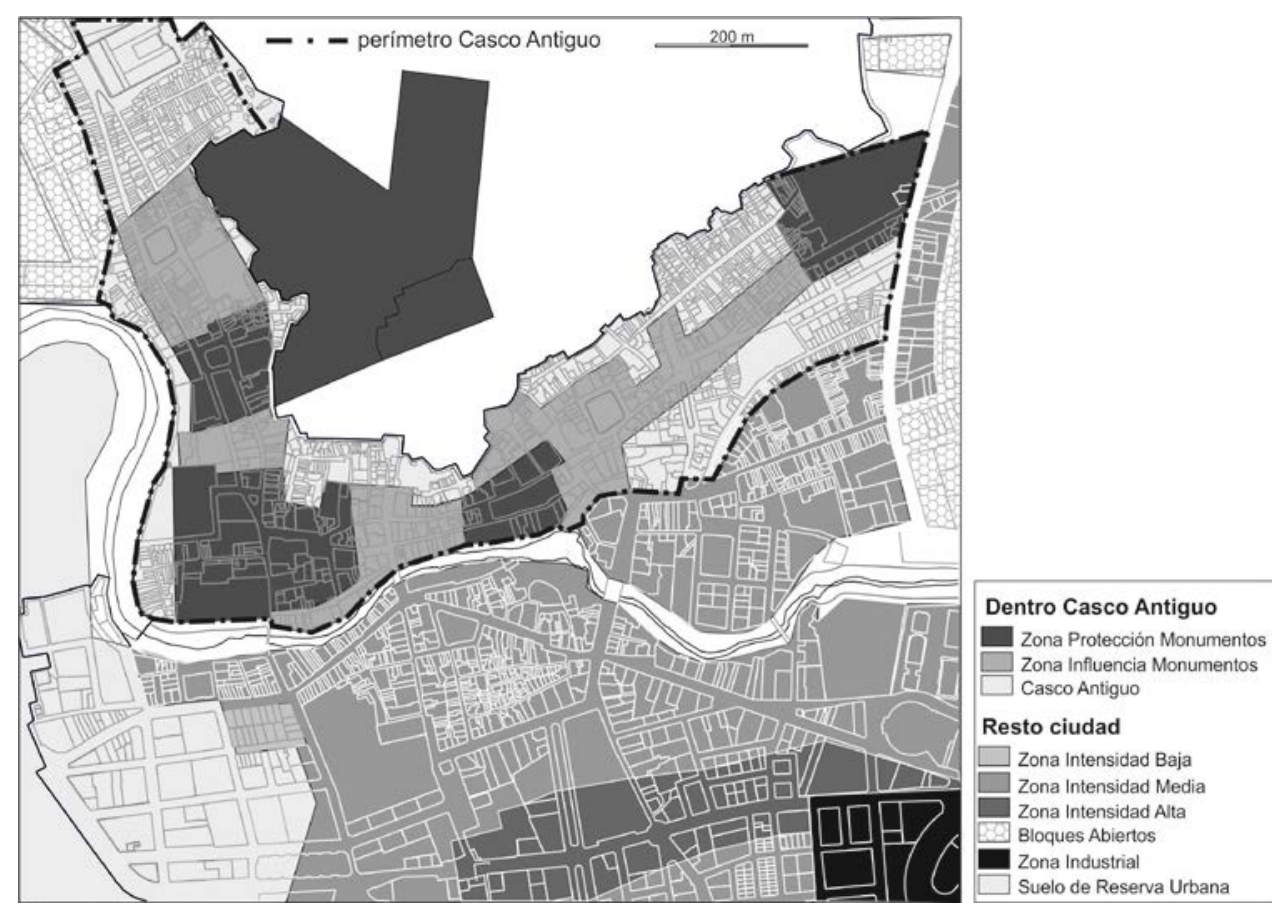

Fuente: elaboración propia a partir del PGOU 1968

\subsection{Monumentos y áreas de influencia}

El PGOU define gráficamente el perímetro del "casco antiguo" que al año siguiente el Decreto de 1969 despachaba como "sector antiguo de la ciudad". Es amplio espacio que se ajusta mucho a los límites de la ciudad a finales del s. XVIII (Figura 1). No obstante deja fuera los arrabales renovados por los crecimientos del s. XX: San Juan y San Agustín en franco proceso de transformación y ganancia de centralidad en esos momentos (Figura 3).

Dentro del perímetro establece cinco áreas como Zona de Protección de Monumentos, que envuelven el castillo, las iglesias de Santiago y de Santas Justa y Rufina, la catedral y el colegio de Santo Domingo. Alrededor de las mismas establece unas Zonas de Influencia de Monumentos que son, en definitiva, los espacios sustraídos a la gestión del PGOU y delegados a la tutela de la Comisión Provincial del Tesoro Artístico. La delimitación de áreas de influencia era precepto obligado en cumplimiento de lo dispuesto en el artículo 60 de la Ley sobre Régimen del Suelo de 1956, donde se explícita que "Las construcciones en lugares inmediatos o que formen parte de un grupo de edificios de carácter artístico, histórico, arqueológico, típico o tradicional habrán de armonizar con el mismo" (BOE n. ${ }^{\circ} 135,14$ de mayo de 1956). 
El resto era calificado como Casco Antiguo común, sin ningún catálogo ni reglamentación específica, salvo la derivada de la intensidad del uso residencial, que también afectaba a las zonas de protección e influencia de monumentos, definida tan sólo por el criterio de la sección de la calle. La anchura del vial es criterio ya defendido por las comisiones sanitarias y las normas recogidas en el Reglamento de obras, servicios y bienes municipales de 1924, en su cap. III "De las obras de mejora interior de poblaciones", 3 donde se especificaba que los inmuebles que se construyan no podrán tener altura superior a la anchura de la calle, y si ésta está corregida y alineada, como máximo la altura de vez y media la anchura de la calle, indicándose que la altura de una planta no podrá ser nunca inferior a 2,80 m (art. 23). Principio que no se mantendría en Orihuela, donde la edificabilidad en relación con el ancho de calle fue siempre más generosa.

En el Cuadro 1 se recoge la altura permitida en los nuevos edificios según las zonas establecidas. La zona histórico-artística engloba las cartografiadas como zona de protección y zona de influencia de monumentos. Es ámbito antiguo donde ninguna calle supera los $15 \mathrm{~m}$ de sección: las dos principales calles -Dr. J. M. Sarget y Mayor-cuentan con 7 m y 4 m en su mayor sección. De ahí que la generosa regulación de alturas para calles de menos de 9 m de sección se extendiese prácticamente a todo el ámbito supuestamente protegido: hasta 4 alturas (unos $12 \mathrm{~m}$ de alzado), que podían fácilmente duplicar (o más) el aprovechamiento del suelo urbano.

En sí misma, esta generosa regulación de las alturas, era acicate suficiente para la renovación del caserío, mediante la sustitución de casas bajas o de dos plantas por otras de mayor altura. Más aún si se tiene en cuenta que la medida de la anchura de la calle, que debía ser referencia de la altura del edificio, se tomaba en el punto donde debía abrirse la puerta de acceso al nuevo edificio. Así, las puertas buscaban siempre el mejor emplazamiento, a veces frente a plazoletas o esquinazos de mayor amplitud, para ganar edificabilidad. Es el caso (entre otros muchos) del edificio construido en 1970 en la calle Dr. J. M. Sarget que, aprovechando que su puerta de acceso se halla frente a la Plaza del Salvador (frente a la Catedral) consiguió levantar 6 plantas sobre rasante, más ático y sobreático, cuando la calle tiene una sección media de 5 metros y, según los parámetros del PGOU le corresponderían 4 alturas como máximo (ver Cuadro 1).

3 Reglamentos para la ejecución del Estatuto Municipal, aprobado por los Reales Decretos de 2, 10 y 14 de julio y 22 y 23 de agosto de 1924, que sería germen del Proyecto de Ensanche de Orihuela de 1926-1927 (Cap. II "De las obras de ensanche y extensión de poblaciones"). 
Tabla 1. PGOU 1957-1968. Altura edificios: número de plantas (incluida planta baja)

\begin{tabular}{|l|l|l|l|l|l|}
\hline & \multicolumn{5}{|c|}{ ancho de calle } \\
\hline zonas & $30 \mathrm{~m}$ a $20 \mathrm{~m}$ & $20 \mathrm{~m}$ a $15 \mathrm{~m}$ & $15 \mathrm{~m}$ a $9 \mathrm{~m}$ & $9 \mathrm{~m}$ a $7 \mathrm{~m}$ & $7 \mathrm{~m}$ y menos \\
\hline Histórico-artística & - & - & 3 a 5 & 3 a 4 & 3 a 4 \\
\hline Casco antiguo (resto $\mathrm{CH})$ & 5 a 7 & 5 a 6 & 5 a 4 & 3 a 4 & 2 a 3 \\
\hline Intensidad baja & - & 2 a 4 & 2 a 3 & 1 a 2 & 1 a 2 \\
\hline Intensidad media & 3 a 5 & 3 a 5 & 3 a 4 & 2 a 3 & 2 a 3 \\
\hline Intensidad alta & 5 a 7 & 5 a 6 & 5 a 4 & 3 a 4 & 2 a 3 \\
\hline Bloque abierto & 5 a 7 & 4 a 6 & 3 a 5 & 2 a 4 & 2 a 3 \\
\hline
\end{tabular}

Fuente: elaboración propia a partir del PGOU 1957-1968

\subsection{El ajuste del PGOU de 1973 y el crecimiento en altura}

Aunque la renovación especulativa del centro histórico avanzaba, la fuerte dinámica del arrabal de San Juan, convertido en parte sustancial del nuevo centro funcional de la ciudad, y las posibilidades de acoger viviendas protegidas (en bloque) en el Rabaloche, planteaban la necesidad de un tratamiento más específico y acorde con sus nuevas funciones. Esa reconquista urbanística de los espacios históricos se halla en la base de la revisión del PGOU, en 1973, de una ciudad que permanecía estancada demográficamente: 44830 habitantes en 1960 y 44938 habitantes en 1970.

Por lo que respecta al centro histórico, se procedía a definir un nuevo perímetro que yugulaba el anterior conjunto, diferenciando dos grandes partes: una, entorno al colegio de Santo Domingo (para envolver ese monumento nacional), y otra más grande desde el Paseo hasta la calle Capillas (en el Rabaloche), que recogía los otros tres monumentos nacionales de carácter urbano. Sin embargo, la superficie total de suelo afectado no se modificaba, al compensar las pérdidas mediante la incorporación de una estrecha franja en la margen derecha del río Segura, que hasta entonces había sido límite perceptivo del centro histórico (Figura 4).

La ampliación recaía sobre los huertos del río (espacio no urbanizado) ubicados en el paraje rural denominado Senda del Obispo (al oeste del centro histórico), y por la alineación de manzanas que definían el cauce urbano del río en el antiguo arrabal de la Mancebía, dejando fuera el gran arrabal histórico de San Agustín (espacio de centralidad). De ese modo, el Segura comenzaba a dejar de ser frontera para convertirse, paulatinamente, en eje central del espacio histórico. Bien que todavía con su primigenio aspecto de cauce natural, invadido y yugulado por las construcciones ribereñas, que lo usaban como albañal y vertedero. 
Figura 4. PGOU 1973: Casco Antiguo

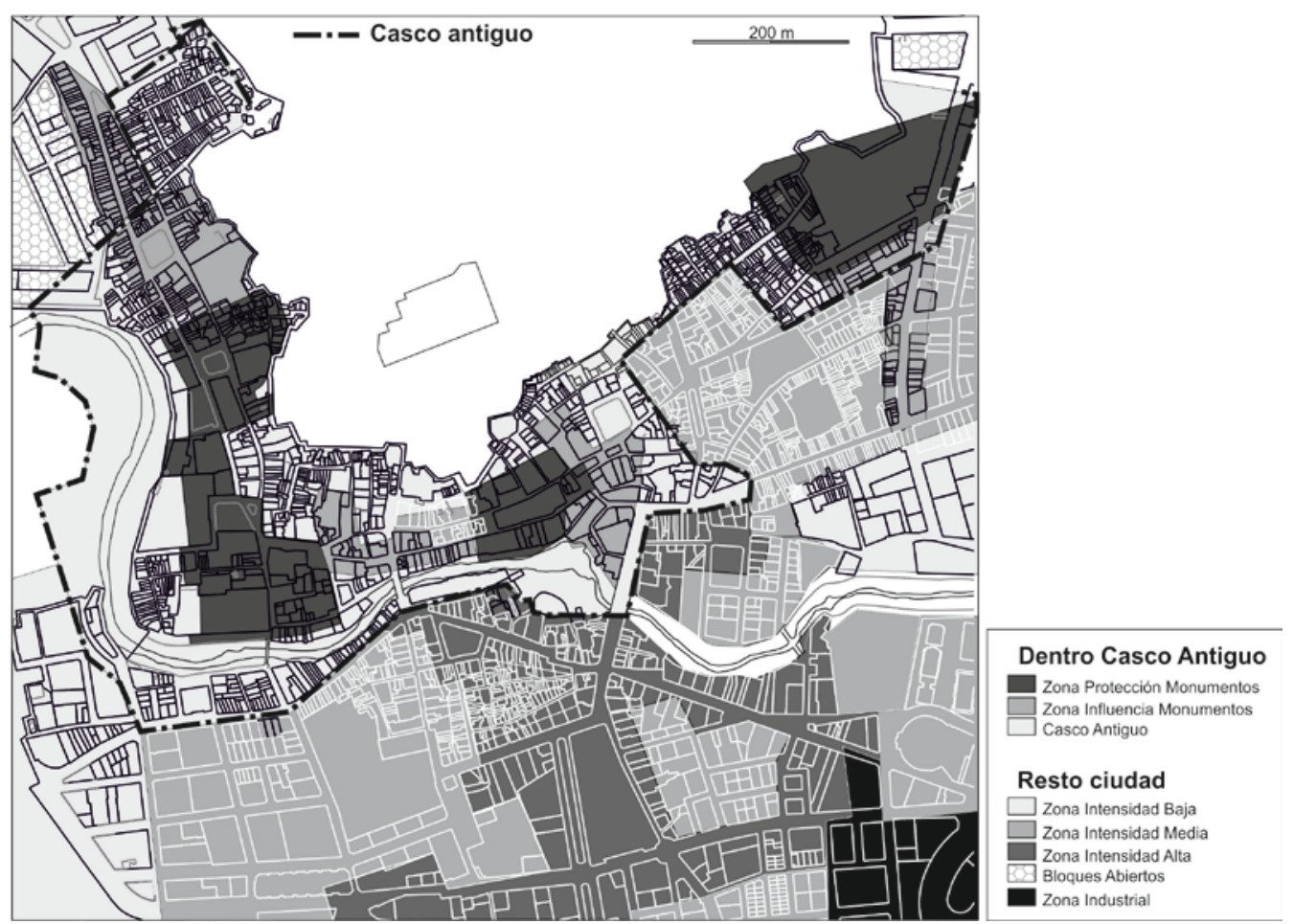

Fuente: elaboración propia a partir de la rectificación del PGOU (1973)

La revisión del plan general mantiene las zonas de protección e influencia de monumentos, señalando su tutela por la Dirección de Bellas Artes, con un supuesto mayor control en la edificación en altura, que se regula como sigue: "la altura máxima de las edificaciones será la dominante en la calle o plaza, con un máximo de 14,5 m"; cuando en el anterior PGOU se limitaba la altura máxima en $12 \mathrm{~m}$. En el resto, es decir, en el casco antiguo común, se matizaban los criterios anteriores de ancho de calle para facilitar la construcción en altura, manteniendo el mismo generoso criterio del plan general anterior (Tabla 2).

Tabla 2. Rectificación PGOU 1973. Altura edificios: número de plantas (incluida planta baja)

\begin{tabular}{|c|c|c|c|c|c|c|}
\hline & \multicolumn{6}{|c|}{ ancho calle } \\
\hline zonas & Más de $20 \mathrm{~m}$ & $20 \mathrm{~m}$ a $15 \mathrm{~m}$ & $15 \mathrm{~m}$ a $11 \mathrm{~m}$ & $11 \mathrm{~m}$ a $9 \mathrm{~m}$ & $9 \mathrm{~m}$ a $6 \mathrm{~m}$ & $6 \mathrm{~m}$ a $4 \mathrm{~m}$ \\
\hline Histórico-artística & \multicolumn{6}{|c|}{ Dominante en la calle o plaza (máximo 14,5 m) } \\
\hline Casco antiguo (resto $\mathrm{CH}$ ) & & & 5 a 4 & 4 a 3 & 4 a 3 & 3 a 2 \\
\hline Intensidad baja & 7 a 5 & 6 a 4 & 5 a 3 & 4 a 3 & 4 a 3 & - \\
\hline Intensidad media & 8 a 5 & 7 a 4 & 6 a 4 & 5 a 3 & 4 a 3 & - \\
\hline Intensidad alta & 12 a 10 & 12 a 10 & 10 a 7 & 7 a 5 & 4 a 3 & 3 a 2 \\
\hline Bloque abierto & \multicolumn{6}{|c|}{ Coeficiente de edificabilidad de $3 \mathrm{~m}^{3} / \mathrm{m}^{2}$} \\
\hline
\end{tabular}

Fuente: elaboración propia a partir de la rectificación del PGOU (1973) 
Se ha señalado la interesada exclusión del arrabal de San Juan, que se libera de la regulación de alturas del casco antiguo común y se convierte todo él en zona de intensidad media, es decir, con muy altas expectativas de multiplicar la edificabilidad. Interesada también fue la exclusión del arrabal histórico de San Agustín (Raval Major y Raval del Pont), ubicado en el vector de crecimiento del ensanche, de elevado atractivo residencial y terciario, sobre el que se favorecía una intensa renovación. Así, con el PGOU de 1973 pasaba de intensidad media a zona de intensidad alta, tanto en los bordes del arrabal, donde se permiten edificios de hasta doce alturas, como en el apretado callejero del mismo, apto para todos los usos, "con excepción de los usos industriales" (Figura 4).

\subsection{El primer plan de ordenación urbana para el conjunto del municipio}

Como va dicho, este plan general es el primero que procedía a ordenar con criterios uniformes todo el municipio. Traza un nuevo perímetro del centro histórico, separándolo por vez primera en dos unidades, para dejar fuera el barrio de la Calle de Arriba o de Miguel Hernández (Figura 5), lo que supone una clara declaración de intenciones, que se mantendrá en el posterior plan especial, que afecta a un barrio socialmente muy afectado que, fuera de todo tipo de protección, podría ser renovado urbanística y socialmente.

Define unos nuevos parámetros de edificabilidad que, sin ser permisivos, se ajustan más al proceso de renovación en marcha. A grandes rasgos, fija en 4 las alturas máximas permitidas en el centro histórico, señala zonas de 1 altura ceñidas a las partes más elevadas del callejero, sobre la colina, y luego gradúa el número de plantas detalladamente por calles hacia el llano, donde se alcanzan las 4 plantas. En todos los casos, la altura máxima permitida queda sujeta a no sobrepasar la altura de los edificios catalogados existentes en la manzana. Aunque se explicita que será el plan especial (en elaboración en esos momentos) quien deberá establecer las regulaciones (PGOU, 1990, Art. 1, ámbito de aplicación).

Con este nuevo marco, se superaban los condicionantes impuestos por la anchura de la calle y por las zonas de protección e influencia de monumentos. Así, en la parte baja del centro histórico, con independencia de la proximidad a alguno de los monumentos nacionales o de la sección de la calle, la altura quedaba regulada en 4 plantas, dando uniformidad de cornisa a calles como las que configuran el denominado "eje monumental": secuencia de calles entre el Ayuntamiento y el museo de Semana Santa, junto al Paseo. 
Figura 5. PGOU 1990: perímetro del centro histórico y altura de las edificaciones

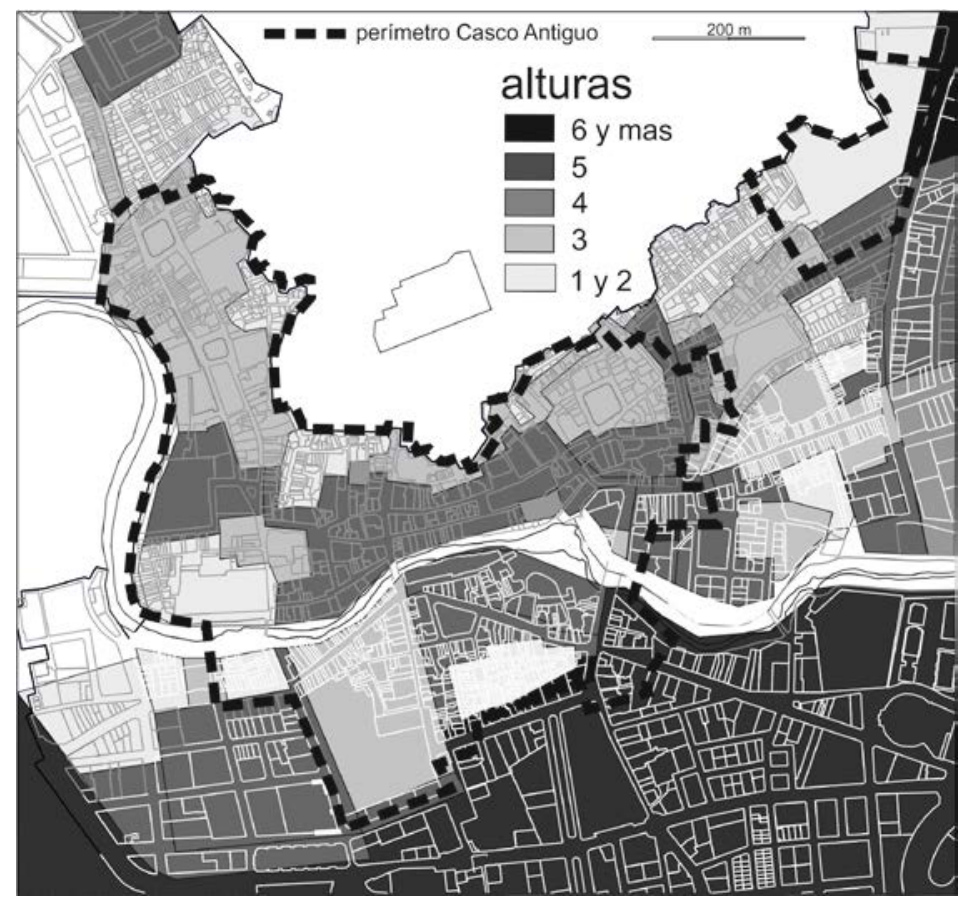

Fuente: elaboración propia a partir de las Normas Urbanísticas PGOU (1990)

Con el plan general se aprobaba el primer "catálogo" de edificios del municipio, que contenía 228 fichas, de las cuales 128 en el casco urbano y, de ellas, 106 en el centro histórico. Con una normativa que permitía la adecuación a los nuevos usos y, en la mayor parte de los casos, la sustitución completa del edificio (Tabla 3).

Tabla 3. Catálogo de edificios protegidos (1990)

\begin{tabular}{|c|c|c|c|l|}
\hline \multirow{2}{*}{ nivel } & \multicolumn{3}{|c|}{ elementos } & \multirow{2}{*}{ parámetros protección } \\
\cline { 2 - 4 } & urbanos & no urbanos & total & \\
\hline 1 & 11 & 5 & 16 & integral, pero adaptable a las nuevas funciones \\
\hline $2 *$ & 28 & 24 & 52 & fachadas y cubiertas, pero adaptable a las nuevas funciones \\
\hline $3^{*}$ & 32 & 28 & 60 & $\begin{array}{l}\text { ambiental, adaptable nuevas funciones, renovación planta baja (uso } \\
\text { comercial) y sustitución elementos fachada }\end{array}$ \\
\hline 4 & 57 & 43 & 100 & $\begin{array}{l}\text { ambiental, admite demolición y sustitución por nuevo edificio "que } \\
\text { mantenga el criterio original" }\end{array}$ \\
\hline totales & 128 & 100 & 228 & \\
\hline
\end{tabular}

Leyenda: * podrán demolerse por ruina o para reconstruirse como el original.

Fuente: elaboración propia a partir del Catálogo PGOU (1990)

\section{El plan especial de 1994}

Con evidente retraso respecto a otros centros históricos valencianos, que iniciaron sus estrategias de recuperación a principios de los años 1980 (Boira, 1995; Gaja, 2001), el Plan Especial de Ordenación y Protección del Centro Histórico de Orihuela -PEOPCH- se aprobaría en 1994 
(Figura 6). Impulsado más por cuestiones administrativas que por voluntad política, como se desprende de su Memoria. El detonante fue la aprobación, en 1990, del nuevo plan general que remitía todo lo concerniente al ámbito histórico a la redacción de un plan especial, conforme con las obligadas prescripciones de la recién inaugurada Ley sobre Reforma del Régimen Urbanístico (8/1990, de 25 de julio), del Reglamento de Planeamiento y a tenor de lo dispuesto en la Ley del Patrimonio Histórico Español (16/1985, de 25 de junio).

Figura 6. PEOPCH de 1994

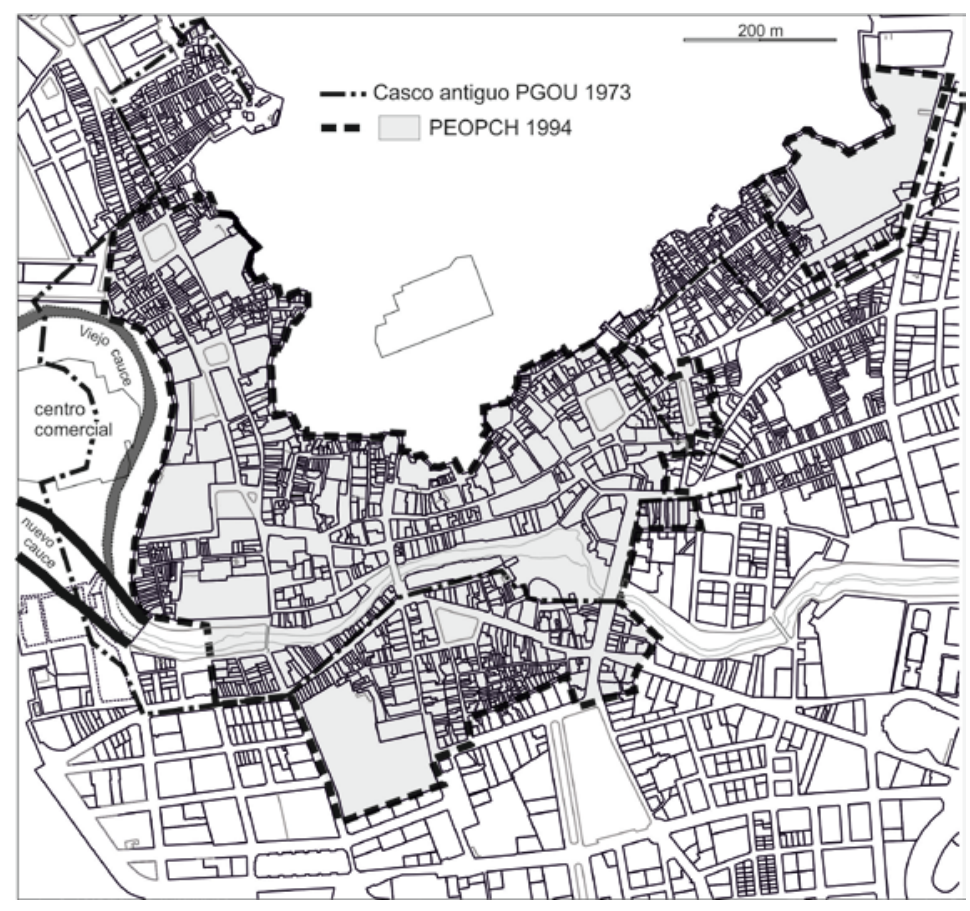

Fuente: elaboración propia a partir del PEOPCH de Orihuela (1994)

En su tramitación se interpusieron las obras de canalización del río Segura a su paso por mitad del centro histórico (Plan general de defensa frente a inundaciones de 1987), que abrirían una importante brecha en el viejo callejero, por la demolición de algunas manzanas ribereñas, que estrangulaban el cauce natural y favorecían el aumento de la ola de crecida y su desbordamiento (Juárez, Ponce, Canales, 1989).

Esas grandes obras de infraestructura también ocasionaron la eliminación del meandro de la Senda del Obispo, donde el río ceñía la antigua muralla árabe (Torre de Embergoñes, zona del Rabaloche). El cambio en el curso del río (Figura 7) supuso una significativa alteración de la zona delimitada como centro histórico. Todo el espacio liberado fue extraído del perímetro y clasificado como Suelo Urbano para equipamientos, donde se levantaría un complejo deportivo público, una zona comercial privada (Ociopía) y un área de aparcamientos para dar servicio tanto a los nuevos equipamientos como a la zona administrativa del centro histórico. 
Figura 7. Acondicionamiento de las riberas urbanas del Segura (Plan defensas, 1987).

El mismo tramo antes y después de las reformas

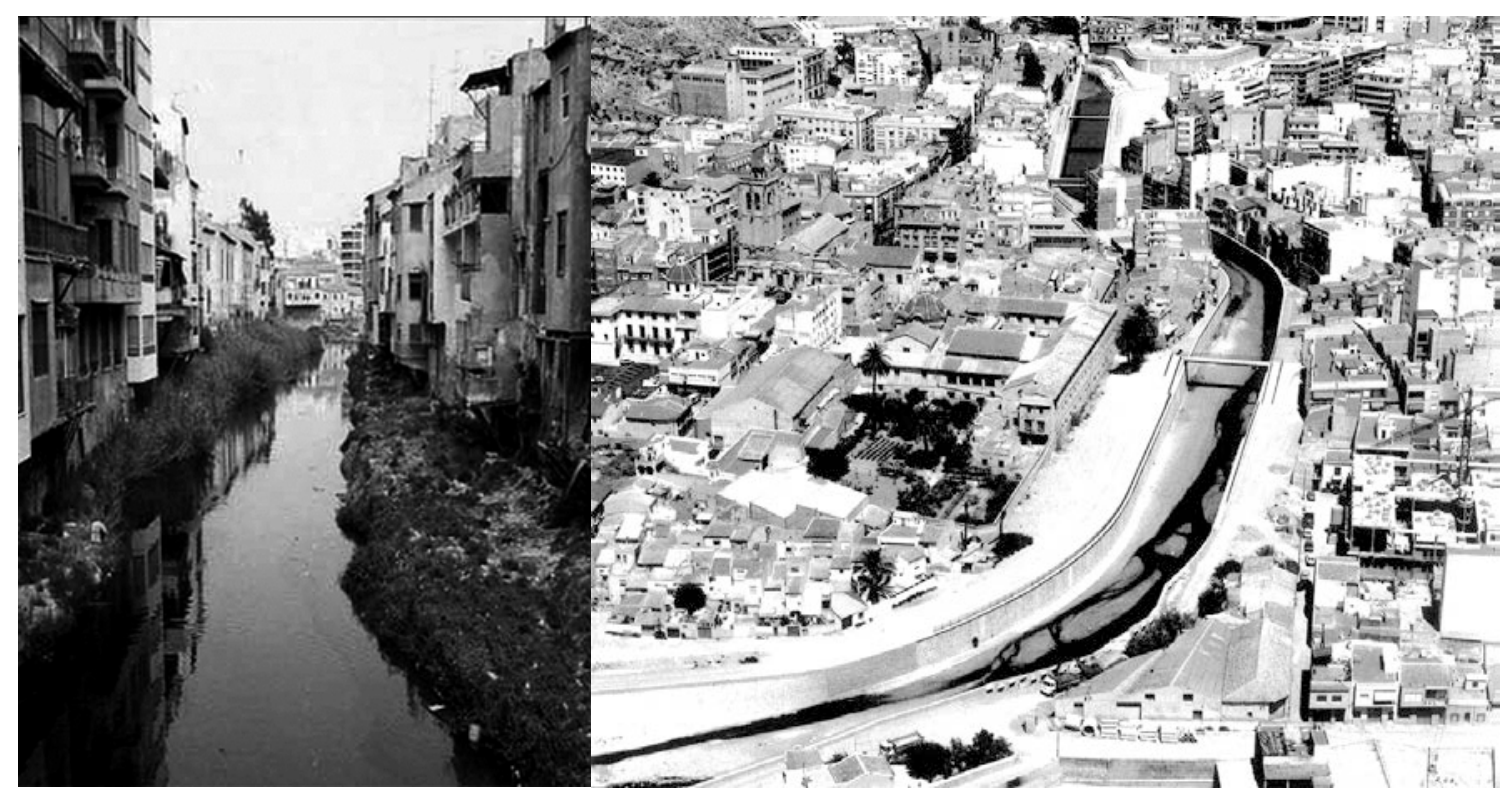

Fuente: Confederación Hidrográfica del Segura

Figura 8. PEOPCH de 1994: alturas

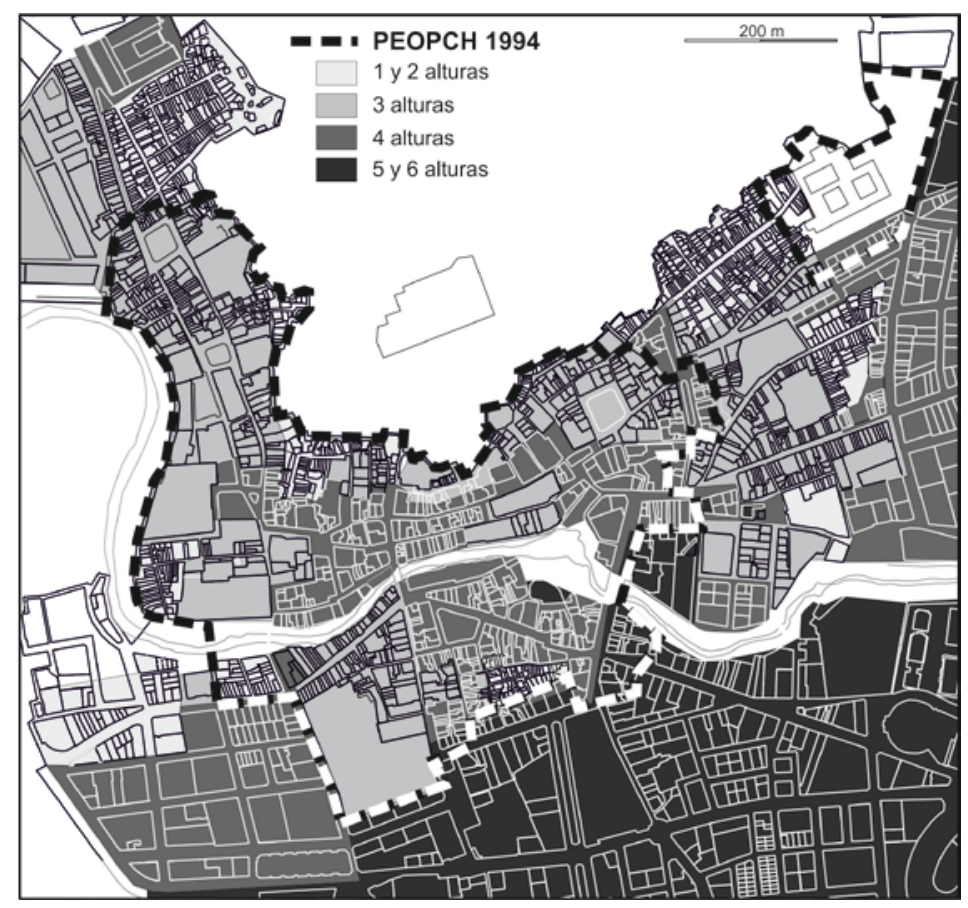

Fuente: elaboración propia a partir del PEOPCH de Orihuela (1994)

La pérdida de "suelo histórico protegido" fue compensada en el PEOPCH mediante la incorporación de los antiguos arrabales del Pont y Major (o de San Agustín), en la margen derecha del Segura, que ya habían experimentado una gran transformación debido a su centralidad y a su alto valor funcional como nexo que une el caserío antiguo con el ensanche del s. XX. Al tiempo, en 
una singular decisión que cortaba en dos el conjunto histórico-artístico de 1969 (conforme a los criterios del PGOU), el arrabal de San Juan (incluido el barrio de la Calle de Arriba o de Miguel Hernández) quedaron fuera del perímetro del PEOPCH y, por tanto, el colegio de Santo Domingo (antigua Universidad) separado del núcleo monumental, acotado de manera aislada, con un eximio espacio de protección (que no fue óbice para acometer las demoliciones y renovaciones necesarias para dejar exentos los muros de la antigua Universidad: se eliminaba el contexto modesto y molesto) y crear una nueva plaza que diese visibilidad al Centro de Estudios Hernandianos (año 2002) y, junto a él, al nuevo producto turístico de la casa de Miguel Hernández museizada (en 2010).

Con un criterio más ajustado tanto a la importancia de las piezas arquitectónicas, como al conjunto, el PEOPCH establecía una nueva volumetría (Figura 8) que, en esencia, fijaba en tres las alturas para el conjunto del centro histórico. No obstante, en sus principales arterias, independientemente de su sección, permitía cuatro alturas, como en todo el "eje monumental". Así mismo, establecía como criterio homogéneo las dos alturas en todo el callejero más pegado al cerro de San Miguel, conforme con la tradición y en beneficio de la conservación del paisaje de ese hito y de la visibilidad de sus principales elementos: el seminario y el castillo.

Fuera del nuevo recinto del centro histórico, en el antiguo arrabal de San Juan se consolidaban las tres y cuatro alturas como norma. Mientras para la Calle de Arriba se establecían dos alturas, conforme tanto con el contexto, como por su ubicación junto al monte. Por su parte, en el arrabal de San Agustín se rebajaban las alturas a dos en su centro, que ha conservado el entramado medieval y a cuatro en sus bordes, cuando antes eran posible hasta diez alturas (así, el paisaje urbano del barrio se halla muy afectado por la impronta de tremendas medianeras).

\section{Los cambios de criterio y las afecciones del centro histórico}

El plan especial, precisamente por su tardía redacción, proponía una gestión integrada del espacio morfológico, funcional y social acotado. Así, incorporaba entre sus objetivos los de mejorar la calidad urbana, las condiciones ambientales y la habitabilidad para recuperar la vida y las funciones y, además, el de "poner el centro al servicio de los ciudadanos" (PEOPCH, 1994, p. 20). Esto es, se asumían a conciencia las nuevas directrices de la denominada "urbanística de la recuperación", con una visión integrada del centro histórico, más allá de su reconocido valor monumental (Ferracuti, 1983, p. 34). Con ese enfoque más social, además de asumir el Catálogo del PGOU de 1990, proponía también la recuperación de los espacios "menos valiosos", de sus barrios populares para la vida, de su centro para recuperar las funciones de centralidad y del conjunto en relación con el resto de la ciudad, afectada por una potente tendencia centrífuga en favor de las periferias urbanizables. En este punto, el plan especial ha sido criticado por considerar que se centraba más en criterios arquitectónicos que urbanísticos (favoreciendo la demolición y sustitución de los elementos no catalogados), sin una adecuada estrategia de incorporación de servicios de 
urbanísticos y equipamientos de proximidad para la mejora de su medioambiente y habitabilidad general, de forma que las propuestas resultarían ineficaces para su adecuada revitalización e inserción en las dinámicas urbanas del conjunto de la ciudad (Andrés, 2012).

A esa circunstancia coadyuva el hecho de que en Orihuela, como en otros casos valencianos (Boira, 1995, p. 245), las nuevas directrices no fueran aplicadas con uniformidad, ni con la misma intensidad, sujetas a los condicionantes sociales y políticos, a los tipos de formulaciones y proyectos, y a los cambiantes objetivos de las políticas locales, e incluso regionales, al albur de los cambios del signo político de los gobernantes. ${ }^{4}$

Antes del plan especial, el rico patrimonio urbano y arquitectónico de la ciudad quedó muy afectado por la laxa normativa de los planes generales del desarrollismo (PGOU de 1968 y 1973) centrados sobre todo en el diseño de ciudad nueva, con un clamoroso olvido de las conexiones de movilidad, pero también sociales y funcionale- con la ciudad histórica, así cada vez más afectada por la despoblación, las disfuncionalidad, el abandono y la ruina. ${ }^{5}$

\section{Figura 9. Plan de acción comercial de Orihuela y áreas del centro histórico}

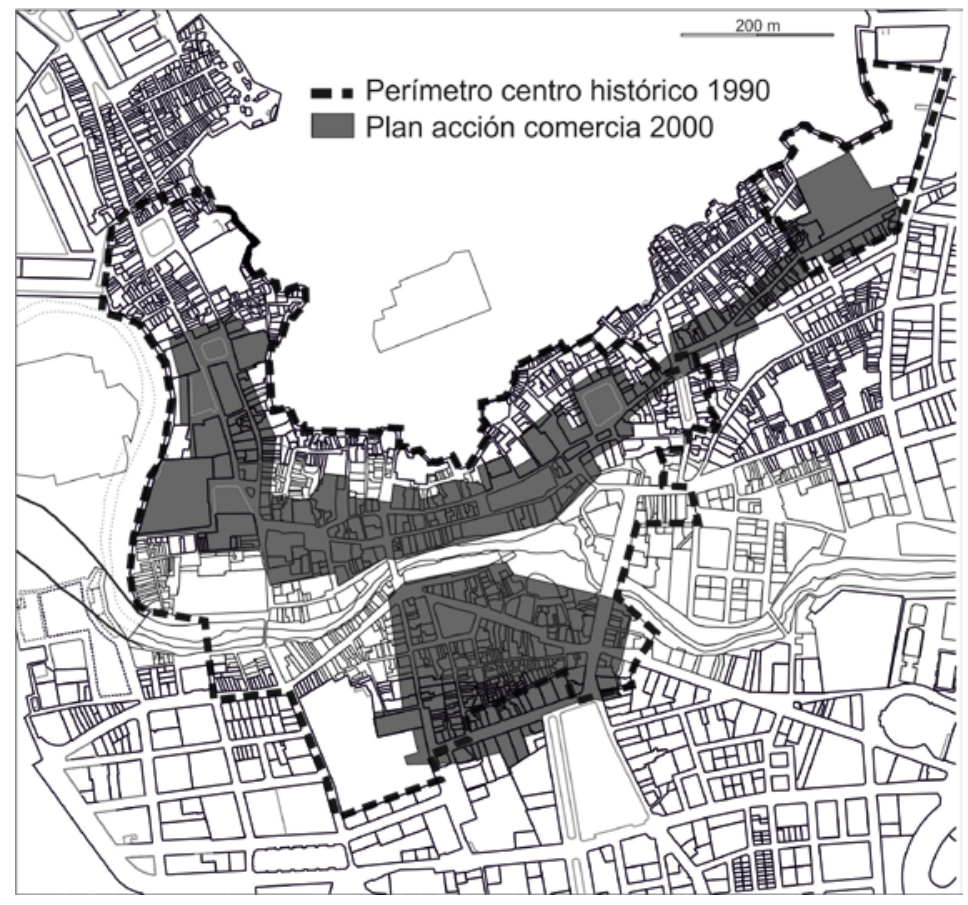

Fuente: elaboración propia a partir de PATECO (2000)

4 El alcalde de la ciudad entre 1987 y 1994, fecha de impulso del PEOPCH, fue luego Conseller de Obras Públicas, urbanismo y Transporte del Gobierno Valenciano, entre 1995 y 1999, etapa en que algunas de las propuestas del PEOPCH fueron sustituidas por grandes proyectos urbanísticos, como la construcción de un campus universitario.

5 PEOPCH (1994, p. 18): "La degradada situación actual del Centro Histórico y la necesidad de contar con un instrumento de planeamiento acorde a la legislación vigente... El importante proceso de sustitución y vaciamiento que ha sufrido la ciudad en los últimos 20 años... son las causas de redacción de este Plan Especial". 


\subsection{La falta de uniformidad para la definición de un espacio funcional}

Los cambios de criterio se manifiestan también en la diferente definición del espacio considerado histórico en la secuencia del planeamiento local, aunque aproximadamente se mantiene su extensión: 33 Ha en 1968, 30,3 Ha en 1973 y 32,4 Ha en 1990-1994, bien que sobre diferentes espacios históricos, que valoran siempre el "eje monumental" pero difieren al tratar sus bordes, por lo general muy afectados socialmente. Se trata de un fenómeno coincidente con el concepto de "áreas centrales antiguas" (Luque y Smith, 2007), por el que se diferencia claramente lo monumental de las demás partes que, aunque antiguas, no perciben la misma valoración ni ciudadana ni técnica. De ese modo, en Orihuela, las estrategias para una y otras áreas centrales antiguas han variado desde la rehabilitación más exquisita hasta casi el abandono a su suerte, pasando por potentes estrategias de renovación de las áreas antiguas de mayor centralidad.

El núcleo genético de la ciudad -eje entre Catedral y Ayuntamiento- es el que ha desarrollado las funciones de centralidad y al que se alude popularmente como centro histórico (o eje monumental), extendido por unas $12 \mathrm{Ha}$ cuajadas de monumentos, palacios y edificios religiosos. Mientras que los antiguos arrabales (Calle de Arriba, San Juan, San Agustín y Rabaloche) más humildes, se diluyen en la percepción ciudadana y, por ello, pueden escamotearse a las propuestas de regulación más estricła y, también, a las inversiones y propuestas estratégicas.

Un claro ejemplo se recoge en el Plan de acción comercial de Orihuela (PATECO, 2000), en el que se definían zonas de alto interés, dentro de las áreas centrales antiguas, para concentrar las mejoras urbanísticas que debían potenciar las funciones terciarias (Figura 9). El plan centraba sus propuestas en el eje monumental y en el arrabal de San Agustín -junto al ensanche moderno-, las áreas más afectadas por la renovación y el aumento de la edificabilidad.

En sentido opuesto, el Plan de revitalización de barrios en el casco histórico 2009-2019, necesario por las dificultades para la regeneración social de las otras áreas centrales históricas, se ceñía a los ámbitos de morfología más humilde, ajenos al mercado especulativo del suelo, con abundantes edificios abandonados, en mal estado y en ruina, que constituyen ámbito de atracción para las clases sociales más desfavorecidas (Figura 10). Se trata todavía hoy de zonas degradadas, pese a las propuestas del PEOPCH de 1994, con elevada presencia de inmigrantes de países en desarrollo y minorías étnicas, muy afectados por el desempleo, lo que repercute en considerables índices de pobreza, notables carencias educativas en los padres y absentismo en los menores, y se refleja en procesos de exclusión social y tasas más elevadas de delincuencia. 
Figura 10. Plan de revitalización de barrios en el casco histórico 2009-2019

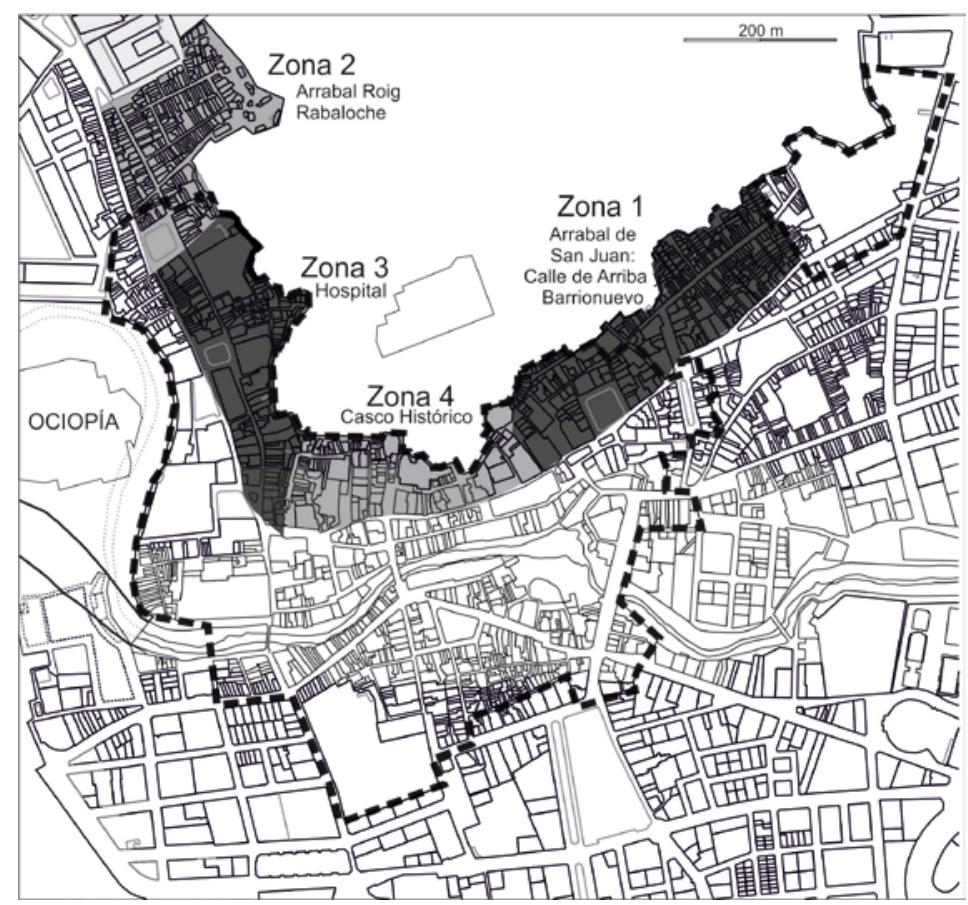

Fuente: elaboración propia a partir del Ayto. Orihuela (2012)

El plan de revitalización definía su ámbito de actuación en los barrios ubicados en la ladera del Monte de San Miguel: San Isidro, Capuchinos-Rabaloche, Casco Histórico, Calle de Arriba y Arrabal de San Juan... ya identificados como Barrios Vulnerables por el Ministerio de Fomento. En opinión del concejal responsable, el "objetivo último del Plan era la revitalización de esos barrios con la finalidad de conformar un gran eje turístico, monumental y comercial" (Rodríguez, 2012, p. 154). Para ello se ponían en marcha estrategias sectoriales urbanísticas y medioambientales de recuperación del espacio público, la incorporación de equipamientos y servicios públicos (desde puestos de policía hasta escuelas infantiles), la rehabilitación de edificios singulares fuera del centro histórico pero en el contexto de las áreas centrales antiguas, la promoción comercial y artesanal mediante escuelas taller y la inclusión de esos barrios en los circuitos turísticos y comerciales.

El plan ha decaído sin apenas actuaciones, más que las financiadas por las administraciones foráneas, como las ayudas genéricas a la rehabilitación de viviendas del Gobierno Valenciano y los Talleres de Empleo del Ministerio de Empleo. Sin duda, la singular inestabilidad política del Ayuntamiento tiene que ver con la sucesión de estrategias para las áreas centrales históricas de la ciudad. También la crisis económica, responsable del nuevo enfoque dado al problema: que sean los fondos europeos los que financien la revitalización social y funcional.

Así, se ha preparado un nuevo plan ajustado a las convocatorias de ayudas, denominado Desarrollo Urbano Sostenible Integrado (DUSI) para ese conjunto de áreas centrales antiguas más desfavorecidas, con un presupuesto cifrado en 30 millones de euros para el periodo 2016-2020. 
Que se pretende financiar a través de la Política de Cohesión de la UE, de los Fondos FEDER, junto con presupuestos locales y ayudas de las administraciones valencianas. ${ }^{6}$ En él se insiste en la conversión de esos barrios en producto turístico (línea estratégica 8), en la recuperación de la arquitectura de esos espacios (línea estratégica 9), en la creación de un centro comercial abierto (línea estratégica 10) y en la regeneración social y urbana de los barrios (las dos últimas líneas estratégicas: 12 y 13) (Ayuntamiento, 2016).

Parece difícil el éxito de un producto turístico centrado en la arquitectura, si no se procede antes a la regeneración social. Pero, incluso aunque tuviera éxito ese nuevo circuito turístico, la función turística que es percibida como excepcional motor de desarrollo por los ayuntamientos, ha sido criticada por afectar a la pérdida de autenticidad de los barrios reconvertidos (de la Calle, 2002; Troitiño, 2003; González, 2005), y por el fomento de la especulación inmobiliaria que acaba por expulsar a los segmentos sociales a los que, paradójicamente, se pretende favorecer (Luque, Smith, 2007). Si bien, la UNESCO considera que la incorporación de equipamientos y servicios y el desarrollo ajustado del turismo "pueden imprimir un notable impulso económico y contribuir así al bienestar de las comunidades y a la conservación de los conjuntos urbanos históricos y su patrimonio cultural sin menoscabo de su diversidad socioeconómica y de su función residencial" (UNESCO, 2011). En todo caso, plan comercial y plan de revitalización explicitan por sí solos la profunda dualidad generada en el perímetro histórico: áreas centrales con potentes estrategias propias y áreas marginales subsidiadas, por las que se diluye el concepto de centro histórico.

\subsection{Recuperación cultural o recuperación de las plusvalías}

La falta de criterio uniforme sobre el patrimonio arquitectónico y urbanístico se plasma también en la dialéctica local entre conservación de los paisajes culturales y renovación de los mismos, para insertar nuevas funciones que mantenga su valor ciudadano y, con él, su valor económico. Es el proceso de recuperación de las rentas de un suelo afectado (Lefebvre, 1974), mediante grandes operaciones de renovación sobre el tejido histórico.

En Orihuela, la mayor mediación social en la regulación de ese mercado del suelo (planes generales y especial posteriores) propondrían, en esencia, el mantenimiento de las funciones específicas de centralidad histórica - simbolismo, cultura, terciario- potenciando, de esa forma indirecta, el atractivo del centro histórico, para una demanda interesada siempre que esos espacios centrales mantuviesen o recuperasen esas funciones específicas de prestigio social, accesibilidad y proximidad a los servicios urbanos de calidad (administración local y regional, campus universitario, museos, bibliotecas y otros centros de cultura, servicios profesionales e incluso el nuevo centro

6 En octubre de 2016, el Ayuntamiento recibía la noticia de que el proyecto había sido dotado con 10 millones de euros de los fondos europeos, y manifestaba que aportaría otros 10 millones de euros (http://www.orihuela.es/orihuela-recibe-10-millones). 
comercial Ociopía suma en ese sentido). Así hallaría explicación la voluntad de recuperar -recrear y renovar - el centro urbano sobre el afectado centro histórico de Orihuela, todavía propiedad de una selecta elite.

El análisis comparado de los valores catastrales de las dos grandes zonas en que puede dividirse el centro histórico a efectos de interés urbano-especulativo, pone de manifiesto (Tabla 4) como los indicadores medios de valor catastral resultan siempre más elevados en el sector del centro histórico oeste, que acoge el eje monumental y se halla más sujeto a operaciones de renovación (en ese sentido, muy significativo es el valor medio el suelo ocupado por las viviendas).

Tabla 4. Orihuela 2016. Valores catastrales comparados (euros)

\begin{tabular}{|l|r|r|l|r|r|r|r|r|}
\hline \multirow{2}{*}{} & \multicolumn{3}{|c|}{ inmuebles } & \multicolumn{3}{c|}{ viviendas } & \multicolumn{2}{c|}{ valor suelo ocupado } \\
viviendas
\end{tabular}

Leyenda: * Espacio monumental

Fuente: elaboración propia a partir del Ministerio Hacienda. Delegación provincial catastro

En el caso de Valladolid (Álvarez 2004 y 2015) se recoge una secuencia histórica en la producción social de espacio que se ajusta con gran precisión a la experimentada en Orihuela. La primera etapa abarca el proceso de redacción del primer PGOU (1957-1968), coincidente con el inicio del proceso de pérdida de densidad demográfica y de funciones en beneficio del ensanche al otra lado del Segura. Esa incipiente dinámica sería la desencadenante de la Revisión del PGOU en 1973 y de la segunda etapa del modelo considerado, que abarcaría hasta la aprobación el PG de 1990 y el PEOPCH de 1994. Es periodo guiado por la producción espacial de rentas, apoyado en la renovación intensiva sobre suelo central liberado, mediante el aumento de la edificabilidad.

El PGOU es el documento técnico y legal que hace posible la renovación y la obtención de rentas urbanas. En el caso de Orihuela sirvió para "aclarar" el complejo orden social de la ciudad tradicional, heredada de la jerarquizada sociedad estamental y de sus usos consuetudinarios: privilegios, servidumbres y preeminencias en el orden urbano. La puesta en marcha del proceso de renovación, desde instancias ajenas a la rancia aristocracia ya la lglesia locales, ${ }^{7}$ tuvo la virtualidad de ir allanando esa complejidad social, recogida en el entramado urbano histórico, para producir paulatinamente un espacio social simple (funcionalista) que garantizaba la rentabilidad de las inversiones inmobiliarias.

7 Cabe recordar que tanto los planes generales, como el plan especial fueron impulsados por normas y organismos de fuera, contra los que se resistió la ciudad. 
Figura 11. Precio viviendas en 2016 , euros $/ \mathrm{m}^{2}$ construido

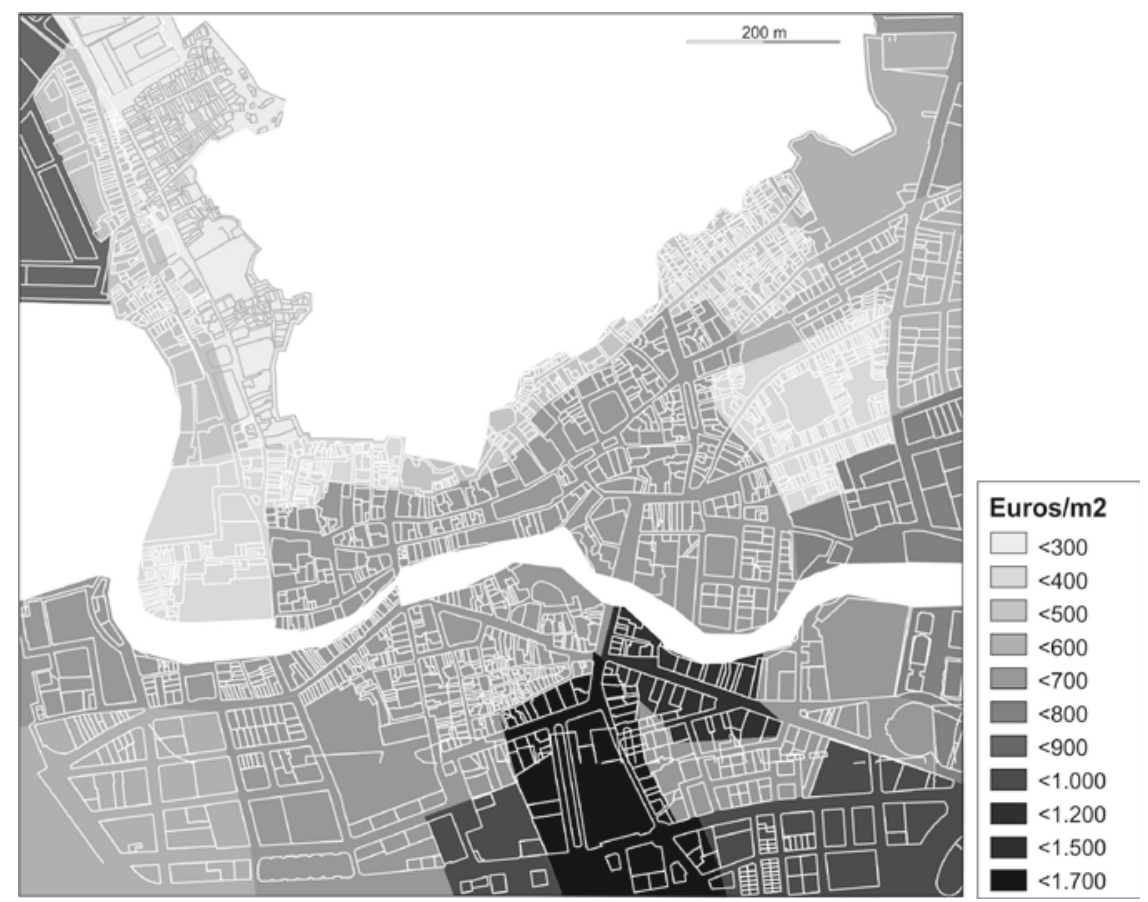

Fuente: elaboración propia

Si los estamentos "casatenientes" se resistían al cambio, la oportunidad de materializar las rentas de posición de sus fincas urbanas actuó como eficaz palanca para su puesta en el mercado y para la inclusión del negocio inmobiliario entre sus nuevas rentas. Ejemplo de palacios enajenados por esos motivos son el del Inquisidor General, de Rubalcava, de Arneva, Fernando de Loaces o Sorzano de Tejada, entre otras muchas fincas urbanas de menor porte, y también los huertos de los conventos de San Juan y de la Trinidad.

El PGOU de 1973 procedía a diferenciar zonas en el conjunto de las áreas centrales históricas, mediante un minucioso proceso selectivo. En aquellas que podían ejercer la función de centro urbano o recuperar la centralidad perdida, se potenciaba la edificabilidad y la posibilidad de renovar también el entramado viario, incorporando nuevos equipamientos y servicios, en un proceso no acabado de generar economías de aglomeración. A las no útiles para esa nueva centralidad, se les asignaba la función residencial (con mucha menor edificabilidad), en un proceso inmobiliario convenientemente ordenado por razones de renta urbana, que definía un área central, coincidente con el centro histórico, y unas áreas periféricas, de menor valor: los otros barrios de las áreas centrales históricas, origen de la actual división social del espacio y de los barrios vulnerables de Orihuela. En ese sentido, es preciso recordar que la renta del suelo se ve directamente afectada (beneficiada o perjudicada) por el contexto urbano y social. Así, mientras el centro histórico se ve favorecido por el alza de precios del suelo, las demás áreas centrales antiguas presentan los precios más bajos de la ciudad (Figura 11). 
Figura 12. Detalle de las alteraciones en el conjunto monumental

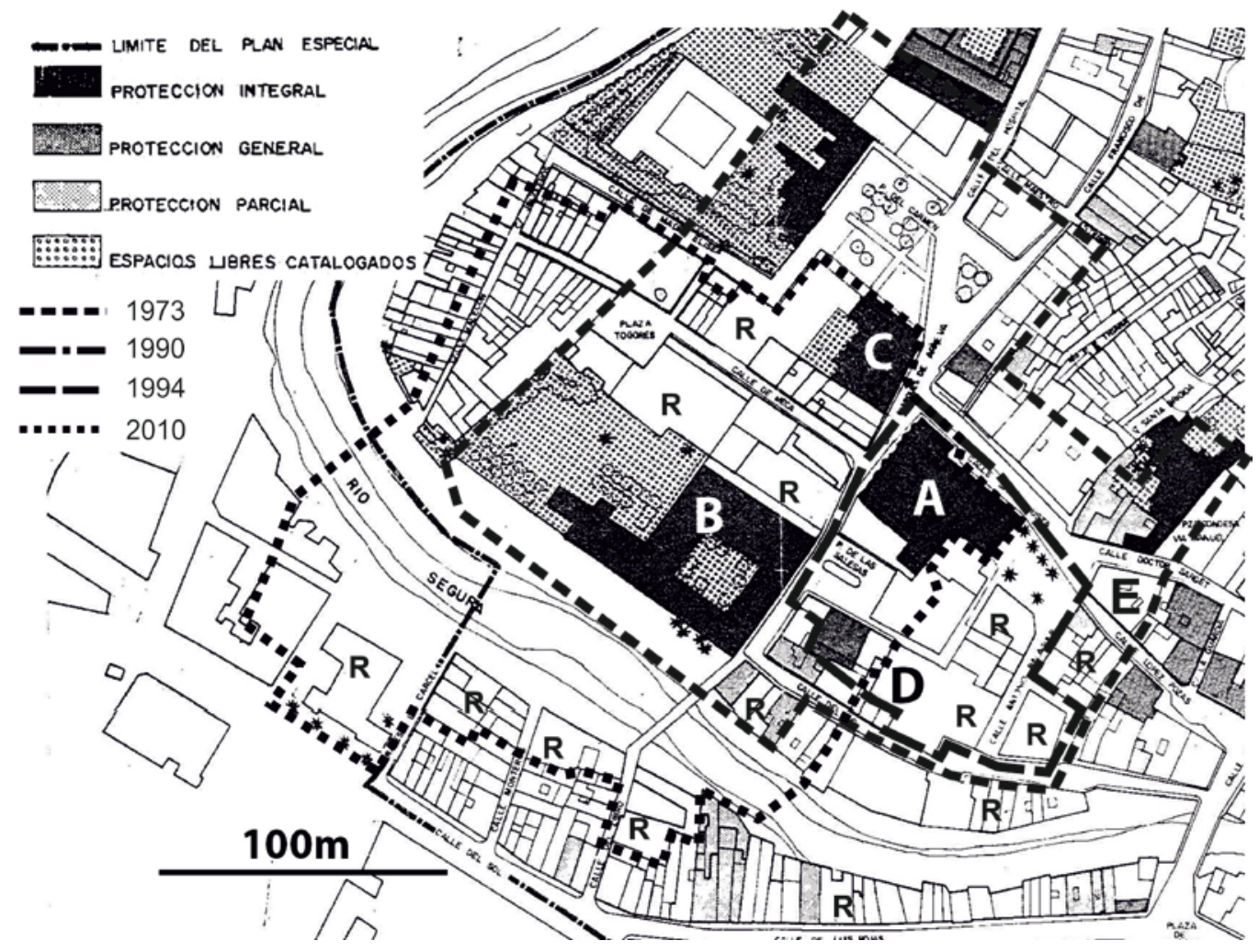

Leyenda: (A) Iglesia Santas Justa y Rufina (Monumento Nacional); (B) Monasterio de Las Salesas (BIC); (C) Palacio del Marqués de Arneva (BIC, ahora Ayuntamiento); (D) manzana sobre la muralla, con edificios particulares de diferente grado de protección, demolida para instalar el campus universitario (año 2000); (E) nuevo edificio del PROP; (R) manzanas renovadas o demolidas. Las líneas marcan el diferente perímetro de protección considerado en cada documento: 1973, PGOU; 1990, PGOU; 1994, PEOPCH; 2010, delimitación BIC Las Salesas.

Fuente: elaboración propia a partir de los documentos citados

La tercera etapa se caracteriza por la debilitación del negocio inmobiliario en el centro histórico, afectado por una nueva normativa administrativa, coincidente con la aprobación del Plan General de 1990 y el PEOPCH de 1994, que restringe el aprovechamiento en las áreas centrales (rebaja general de la edificabilidad, catálogo de edificios, conservación de la trama) al tiempo que pone en el mercado mucho suelo periférico apto para las nuevas demandas del mercado. En ese periodo, los promotores sólo se han interesado de manera muy puntual sobre el centro histórico (nada por las áreas marginales del centro histórico), cuando se ha generado la posibilidad de actuar sobre tejidos urbanos de calidad y/o tradición histórica. Esto es, sobre áreas muy concretas de elevada renta diferencial o de posición, como han sido las manzanas de Santas Justa y Rufina, en el proceso de construcción del campus universitario de Las Salesas (Figura 12), la "manzana de Teodomiro" para instalar el Hotel Meliá, las manzanas en torno al señorial Casino y el nuevo frente fluvial del arrabal de San Agustín (tras la demolición de varias manzanas). También fue oportunidad, si bien fallida para el promotor y para la ciudad, el intento de sustitución de la manzana del Palacio del Inquisidor, derribado en 2002 por su propietario, pese a estar catalogado: la exigua multa 
impuesta por el Ayuntamiento, $66000 €$ por un solar de $1281 \mathrm{~m}^{2}$ en pleno eje monumental, lejos de disuadir, animaba a la renovación. ${ }^{8}$

\section{Conclusiones}

El centro histórico, pese a estar declarado Conjunto Histórico-Artístico, se vio sujeto a las estrategias de sustitución y renovación características del pensamiento moderno -si se ciñe el discurso a los paradigmas urbanísticos-, afectado localmente por los aspectos socioeconómicos ya denunciados (Gaja, 2001), como la pertinaz indisciplina urbanística del municipio, la escasa valoración ciudadana del conjunto histórico, el interés por ganar las plusvalías de las rentas de situación de los edificios históricos y, por consiguiente, el descrédito local del planeamiento urbanístico que pretendía regular los procesos. En Orihuela, los planes generales proponían la renovación del centro histórico y el incremento de la edificabilidad. Claro debate entre historicismo y conservación -obligada-, frente a positivismo, modernidad y renovación - deseada-.

Si los planes generales de 1968 y 1973 proponían reinventar el centro urbano sobre los cimientos del centro histórico -estrategias de renovación-, a partir del PEOPCH de 1994 la ciudad revisaba sus estrategias hacia su barrio histórico, cada vez más "excéntrico" (fuera de centralidad) y "casco viejo" (alejado del concepto de centro histórico), severamente afectado por la pérdida de las funciones de centralidad, que lo han ido alejando del concepto de centralidad histórica. En ese sentido, significativo ha sido el proceso de "vampirización" que identificaba Gaja en Orihuela (Gaja, 2001, p. 162), entendido como la sustracción de vida y funciones por parte de los nuevos desarrollos urbanos periféricos.

La centralidad histórica de la ciudad no puede considerarse un proyecto urbano social, sino la acumulación histórica de diferentes voluntades: primero de los estamentos del Antiguo Régimen, luego de la pervivencia de rancios privilegios, más tarde por la intervención desde la Administración pública, mediante mecanismos técnicos y legales que han favorecido de manera selectiva la renovación de las funciones de centralidad en un eje, dejando de lado otras grandes zonas de históricas, devenidas en barrios vulnerables. La edificabilidad ha sido motor de la potente renovación del caserío antiguo y su control, a partir de PEOPCH, eficaz mecanismo de conservación, si bien en precario. Las operaciones públicas y privadas se han orientado hacia la recuperación del mito del centro histórico, tanto o más para su puesta en valor turístico, que como producto social coherente.

8 De nuevo otra "institución de fuera", en esta ocasión la Consellería de Cultura, sería la que exigiese primero la reconstrucción del palacio derribado. Aunque finalmente, por la mediación del Ayuntamiento, el expediente se cerró mediante la sanción y la calificación del solar como equipamiento público: plaza. 
Del análisis de la evolución de las áreas centrales históricas de Orihuela, y de los diferentes criterios de intervención aplicados sobre ellas, se concluye que el rico patrimonio arquitectónico y urbanístico de la ciudad se ha visto profundamente afectado por el proceso de obtención de rentas urbanas de los estamentos históricos -aristocracia, nobleza e Iglesia a los que se suman hoy los promotores inmobiliarios-. Las grandes transformaciones se han apoyado en las instancias públicas, actuando sobre pequeños lotes de suelo liberado legalmente (manzanas), forzando las normas existentes mediante actuaciones públicas o subvencionadas dirigidas a seguir favoreciendo las economías de aglomeración de funciones en el centro histórico, y a maquillar el desastre precedente, mediante operaciones de "fachadismo", mobiliario urbano y peatonalización, comunes a otros centros históricos, de cierto interés turístico, pero ajenas a las verdaderas necesidades sociales de los vecinos. Conviene pues reflexionar sobre las capacidades y los límites de la especialización turística asignada, como hito esencial, al centro histórico monumental de Orihuela en la oferta turística subregional, de hecho contemplado en la Estrategia Territorial de la Comunidad Valenciana (Generalitat Valenciana, 2011). 


\section{Bibliografía}

Aledo, J. (1990). Orihuela, ciudad. En J. Aledo y E. Diz Ardid (Eds.), Orihuela, un patrimonio arquitectónico, rural y urbano en peligro (pp. 13-33). Alicante: Diputación Provincial de Alicante.

Álvarez, A. (2006). El mito del centro histórico. El espacio del prestigio y la desigualdad. Puebla: Universidad Iberoamericana de Puebla.

Andrés, J. L. (2012). La ciudad histórica en el proceso de regeneración urbana: el caso de Orihuela. En E. Diz Ardid, G. Lobrano, G. y J. L. Andrés (Dirs.), El gobierno de las ciudades. Democracia y eficacia. Competencia y cooperación en el Mediterráneo (pp. 93-142). París: ISPROM, Ayto. Orihuela, PUBLISUD.

Ayuntamiento de Orihuela (2016). Estrategia de Desarrollo Urbano Sostenible Integrado. Recuperado de http://www. orihuela.es/?s=desarrollo+urbano+sostenible+integrado

Biblioteca Oficial Legistlativa (1924). Reglamentos para la ejecución del Estatuto Municipal, aprobado por los Reales Decretos de 2, 10 y 14 de julio y 22 y 23 de agosto de 1924.

Recuperado de

http://fama2.us.es/fde/ocr/2008/reglamentosParaLaEjecucionDelEstatutoMunicipal 1924.pdf

Bohigas, O. (1986). Reconstrucción de Barcelona. Madrid: MOPU Arquitectura.

Boira, J. V. (1995). La rehabilitación urbana en los centros históricos valencianos. Cuadernos de Geografía, 58, 241-258.

De La Calle, M. (2002). La ciudad histórica como destino turístico. Barcelona: Ariel.

Camagni, R. (2004). Economía urbana. Barcelona: Antoni Bosch editor.

Campesino, A. J. (1989). La rehabilitación integrada de los centros históricos: el reto urbanístico de finales de los ochenta. Investigaciones Geográficas, 7, 7-17.

Canales, G., Salazar, J., y Crespo, F. (1992). Proceso de formación urbana de Orihuela (Alicante). Investigaciones Geográficas, 10, pp. 143-164.

Casar Pinazo, J. I. (Dir.) (1994). Plan Especial de Ordenación y Protección del Centro Histórico de Orihuela, Memoria.

Cervellati, P. L., y Scannavini, R. (1976). Bolonia, política y metodología de la restauración de centro históricos (1973). Barcelona: Gustavo Gili.

Coello, F. (1856). Atlas de España y sus posesiones de Ultramar. Madrid.

CITMA (2014). Estrategia de Vivienda y Regeneración Urbana de la Comunitat Valenciana 2014/2020. Recuperado el 1 de agosto de 2015, de www.citma.gva.es/web/vivienda-y-calidaden-la edificacion/plan-vivienda-y-regeneracion-urbana 
Ferracuti, G. (1983). Aspectos económicos, productivos y de coste de la recuperación de edificios. En F. Ciardini y P. Falini (Eds.), Los centros históricos: política urbanística y programas de actuación (pp. 32-51). Barcelona, Gustavo Gili.

Gaja, F. (2001). Intervenciones en centros históricos de la Comunidad Valenciana. Valencia: COPUT Y UPV.

García, S. (2005). Centros históricos ċherencia del pasado o construcción del presente. Agentes detonadores de un nuevo esquema de ciudad. Scripta Nova, IX, 194(39). Recuperado de http://www.ub.edu/geocrit/sn/sn-194-39.htm

García Fernández, J. (2007). La regulación y la gestión del Patrimonio Histórico-Artístico durante la Segunda República (1931-1939). Revista electrónica de Patrimonio Histórico, 1. Recuperado de hitrs: / / dialnet.unirioja.es/servlet/articulo? codigo $=4013153$

Generalitat Valenciana (2011). Área funcional la Vega Baja. Estrategia territorial de la Comunidad Valenciana. Recuperado de http://www.habitatge.gva.es/documents/20551069/ 91101391/ 43378-7183515_AF_La+Vega+Baja/efe584d4-cac6-4298-b291c55557e72fbc

Gil, A. (1983). La propiedad de la tierra en los señoríos de jurisdicción Alfonsina. Investigaciones Geográficas, 1, 7-24.

Gil, A., y Canales, G. (1988). Residuos de propiedad señorial en España. Perduración y ocaso en el Bajo Segura. Alicante: Instituto Juan Gil-Albert.

González-Varas, I. (2015). La conservación-transformación de los conjuntos históricos: una revisión desde la dimensión metropolitana. Ciudad y Territorio, XLVII(184), pp. 203-218.

ICOMOS (1965): Carta Internacional sobre la Conservación y la Restauración de Monumentos y Sitios (Carta de Venecia, 1964), Venecia 1964. Recuperado de hitp://www.icomos.org/charters/ venice_sp.pdf

Juárez, C., Ponce, G., y Canales, G. (1989). Inundaciones en el Bajo Segura. Cronología de una lucha intermitente frente a una amenaza constante (1946-1987). En A. Gil Olcina y A. Morales Gil (Dirs.), Avenidas fluviales e inundaciones en la cuenca del Mediterráneo (pp. 309-329). Alicante: IUG y CAM.

Lalana, J. L. (2011). El paisaje urbano histórico: modas, paradigmas y olvidos. Ciudades, 14(1), 15-38.

La Parra, E. (1981). Privilegios estamentales y reforma del Clero en la crisis del Antiguo Régimen: la jerarquía de la Diócesis de Orihuela ante la convocatoria de las Cortes de Cádiz. Revista de Historia Moderna: Anales de la Universidad de Alicante, 1, 205-220.

Le Corbusier (1975) [1942]. Principios de urbanismo: la Carta de Atenas. Barcelona: Ariel. 
Lefebvre, H. (2013) [1974]. La producción del espacio. Madrid: Capitan Swig.

Luque, E., y Smith, H. (2007). Novedades y retos en la gestión de centros históricos de Europa, Latinoamérica y el Caribe (1980-2005). Scripta Nova, XI(254). Recuperado de http://www.ub.edu/geocrit/sn/sn-254.htm

Madoz, P. (1846-1850). Diccionario geográfico-estadístico-histórico de España y sus posesiones de ultramar. Madrid: Establecimiento tipográfico de P. Madoz y L. Sagasti.

Martínez, A., y Oliva, J. (2008) Dibujos y arquitectura de Miguel López González. 1932-1968. Alicante: CTAA.

Ministerio de Fomento (2001 y 2006). Catálogo de Barrios Vulnerables. Recuperado de hHp://www.fomento.es/MFOM/LANG_CASTELLANO/DIRECCIONES_GENERALES/ARQ_VIVI ENDA/SUELO_Y_POLITICAS/OBSERVATORIO/Analisis_urba_Barrios_Vulnerables/VC

Moreno, M. (1999). La Diócesis de Orihuela-Alicante en el franquismo: 1939-1975. Recuperado de http://rua.ua.es/dspace/handle/10045/9890

PATECO (2000). Plan de acción comercial de Orihuela. Valencia: PATECO.

Pol, F. (1998). La recuperación de los centros históricos: los debates abiertos. En Vivir las ciudades históricas: recuperación integrada y dinámica funcional (pp. 23-55). Cuenca: Universidad de Castilla-La Mancha.

Ponce, G. (2008). Los centros históricos como espacio de vida. En La inmigración en los centros históricos (pp. 13-44). Alicante: Universidad de Alicante.

Rodríguez, A. (2012). Evolución histórica y estrategia de intervención en el Casco Histórico de una ciudad mediterránea: Orihuela. En El gobierno de las ciudades (pp. 143-156). París: ISPROM, Ville de Orihuela y Publisud.

Sargatal, M. A. (2003). La vivienda en el centro histórico de Barcelona. El caso de la Rambla del Raval. Scripta Nova, VII, 146(069). Recuperado de http://www.ub.edu/geocrit/sn/sn$146 \% 28069 \% 29 . h t m$

Ramos, A., Ponce, G., y Dávila, J. M. (Eds.) (1995). Recuperación de centros históricos, utopía, negocio o necesidad social. AGE, GGU, Universidad de Alicante.

Terán, M. (1976). Prólogo. En E. Ruiz Palomeque, Ordenación y Transformaciones Urbanas del Casco Antiguo Madrileño durante los siglos XIX y XX (pp. 9-11). Madrid: Instituto de Estudios Madrileños.

Troitiño, M. A. (1992). Cascos antiguos y centros históricos. Madrid: MOPU. 
Troitiño, M. A (2003). La protección, recuperación y revitalización funcional de los centros históricos. Ciudades, arquitectura y espacio urbano, 3, 131-160. Recuperado de http://www.publicacionescajamar.es/pdf/publicaciones-periodicas/mediterraneo-economico/3/3 Troitiño, M. A., y González-Varas, I. (2015). Sistemas patrimoniales en región es urbanas y áreas metropolitanas. Ciudad y territorio, XLVII (184), pp. 197-202.

UNESCO (2011). Recomendación sobre el paisaje urbano histórico, con inclusión de un glosario de definiciones. Recuperado de http://portal.unesco.org/es/ev.phpURL_ ID $=48857 \&$ URL_DO=DO TOPIC\&URL_SECTION=201.html

Vera, J. F. (1987). Turismo y urbanización en el litoral alicantino. Alicante: I. Juan Gil-Albert. 